UCRL-ID-1 35785

\title{
Laser Dye Technology
}

\author{
Peter R. Hammond
}

September 1999

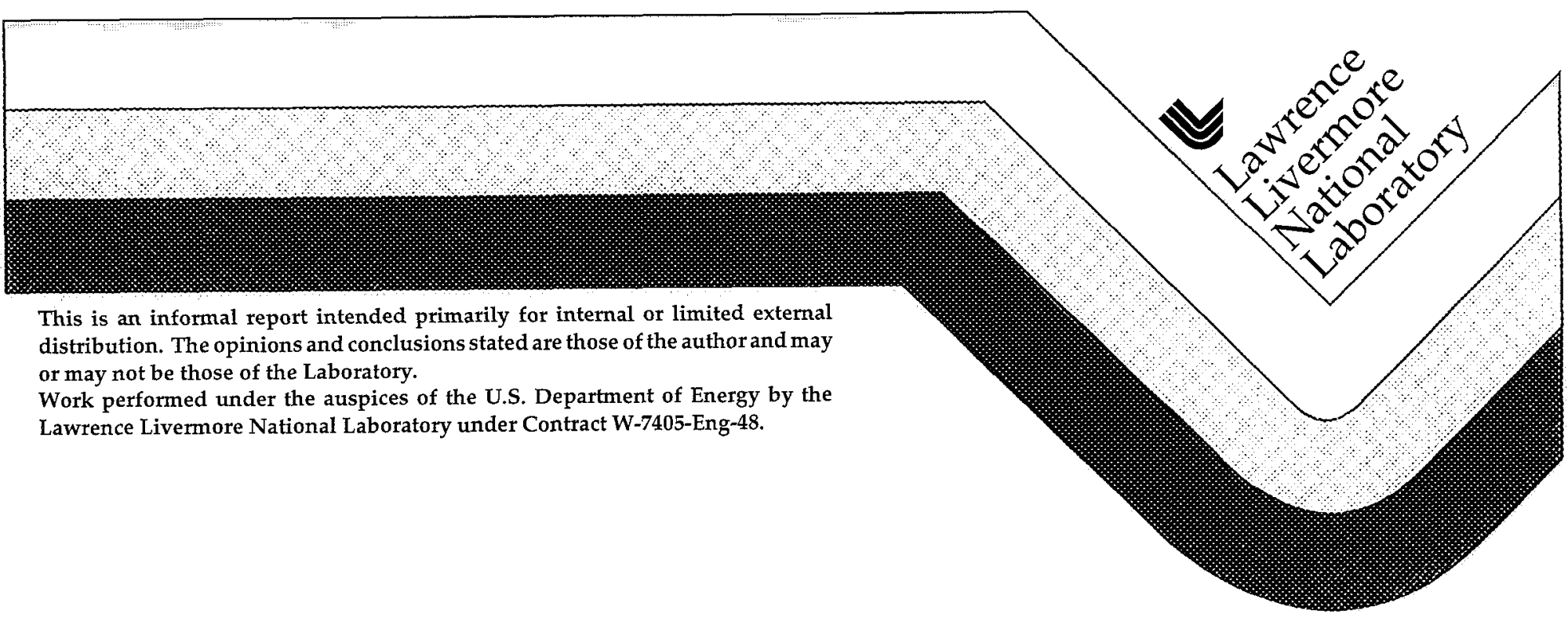




\section{DISCLAIMER}

This document was prepared as an account of work sponsored by an agency of the United States Government. Neither the United States Government nor the University of California nor any of their employees, makes any warranty, express or implied, or assumes any legal liability or responsibility for the accuracy, completeness, or usefulness of any information, apparatus, product, or process disclosed, or represents that its use would not infringe privately owned rights. Reference herein to any specific commercial product, process, or service by trade name, trademark, manufacturer, or otherwise, does not necessarily constitute or imply its endorsement, recommendation, or favoring by the United States Government or the University of California. The views and opinions of authors expressed herein do not necessarily state or reflect those of the United States Government or the University of California, and shall not be used for advertising or product endorsement purposes.

This report has been reproduced directly from the best available copy.

Available to DOE and DOE contractors from the Office of Scientific and Technical Information

P.O. Box 62, Oak Ridge, TN 37831

Prices available from (423) 576-8401

Available to the public from the National Technical Information Service

U.S. Department of Commerce 5285 Port Royal Rd.

Springfield, VA 22161 


\section{Laser Dye Technology}

1. Introduction

2. Dye principles

Saturation fluxes

Emission cross-sections

Tumbling of dye and solvent molecules

3. Dye chemistry

Dye classes

Blue-green dyes

Violet dyes

Red dyes

Deep red, near-infrared dyes

4. Miscellaneous

Dye molecule tweaking

Dipyrrylmethine dyes

Water dyes 


\section{INTRODUCTION}

The author has worked with laser dyes for a number of years. A first interest was in the Navy blue-green program where a flashlamp pumped dye laser was used as an underwater communication and detection device. It made use of the optical window of sea-water - blue for deep ocean, green for coastal water. A major activity however has been with the Atomic Vapor Laser Isotope Separation Program (AVLIS) at the Lawrence Livermore National Laboratory. The aim here has been enriching isotopes for the nuclear fuel cycle. The tunability of the dye laser is utilized to selectively excite one isotope in uranium vapor, and this isotope is collected electrostatically as shown in Figure 1. The interests in the AVLIS program have been in the near ultra-violet, violet, red and deep-red.

\section{DYE PRINCIPLES}

\section{Saturation Fluxes}

I am not going to lecture on customary principles of dye behavior, most of which I am sure you know anyway. Moreover, in the course of this talk I shall have to remind you of some photophysical concepts. We will let them crop up, from time to time, where they may.

Rather my approach is more personal. If a simple-minded organic chemist wanted to make an efficient laser dye what should he aim for? I suggest he should aim for low pump and signal saturation fluxes. The pump saturation flux is that excitation flux able to achieve a $50 \%$ inversion of population. The signal saturation flux is likewise that flux acting on an excited dye that is able to extract $50 \%$ of the stored energy as signal. Elementary equations tell us these fluxes are :

$$
\begin{array}{lc}
\text { Pump saturation flux } & 1 / \sigma_{\mathrm{p}} \tau \\
\text { Signal saturation flux } & 1 / \sigma_{\mathrm{e}} \tau
\end{array}
$$

where they are expressed as photons $/ \mathrm{cm}^{2} / \mathrm{sec}$. For the ubiquitous dye rhodamine $6 \mathrm{G}$ they typically come out about $0.4 \mathrm{MW} / \mathrm{cm}^{2}$. Dyes thus operate more effectively under focussed, laser pumping rather than incoherent excitation as with a flashlamp.

Looking more closely at the parameters of Equations (1) and (2), $\sigma_{\mathbf{p}}$ is the absorption crosssection at the pump wavelength, $\tau$ the fluorescence decay time and $\sigma_{\mathrm{e}}$ is the emission cross- 
section at the signal wavelength. The cross-section $\left(\mathrm{cm}^{2}\right)$ is the physicists method of measuring spectra. From the basic Beer's Law equations :

$$
\begin{gathered}
-\log _{10} I_{I_{0}}=A=\varepsilon c l \\
-\ln I / I_{0}=\sigma N I
\end{gathered}
$$

the chemist relates absorbance $\mathbf{A}$ to molar absorptivity $\varepsilon$ and molar concentration $\mathbf{c}$, whereas the constants we are using here apply to the number of molecules/cc N. Molar absorptivity at the pump wavelength $\varepsilon_{\mathrm{p}}$ is related to the absorption cross-section $\sigma_{\mathrm{p}}$ by :

$$
\varepsilon_{\mathrm{p}} \quad=2.616 \times 10^{20} \sigma_{\mathrm{p}}
$$

Figure 2 shows the absorption and fluorescence spectra of thodamine 6G. The pump saturation flux is lower near the peak absorption than on the tail of the band. This dye is conveniently pumped by the copper vapor laser green line at $510.6 \mathrm{~nm}$ and particularly by the doubled neodymium laser line at $532 \mathrm{~nm}$, which sits right on the maximum. The mirror-image fluorescence gives us some idea of the induced emission spectrum and similar arguments apply, but more about that later.

The fluorescence decay time $\tau$ is related to the natural or radiative lifetime $\tau_{\mathrm{N}}$ by the fluorescence quantum yield $\mathbf{Q}$.

$$
\tau=\mathbf{Q} \tau_{\mathrm{N}}
$$

The higher the fluorescence quantum yield, the closer $\tau$ is to $\tau_{N}$, and hence the lower the pump and signal saturation fluxes. The best dyes have $\mathbf{Q}$ values as close to 1.0 as can be measured, but such are few, although there are chemical tricks we can use to optimize quantum yield. Rhodamine 6G (Figure 2) shows a marked spectral overlap; at the peak absorption there is a strong fluorescence and at the peak fluorescence there is a strong absorption. A fluorescence photon has a possibility of reabsorption by ground-state dye, prolonging the decay time. Such prolongation can be as much as $40 \%$ (Reference 1 ), which complicates attempts at dye performance modelling, particularly when there is marked population inversion and nonradiative energy transfer. Also the absorption/fluorescence overlap interferes with the dye laser output wavelength and forces it towards the tail of the emission band. 
The natural lifetime $\tau_{\mathrm{N}}$ is related to the dye oscillator strength $\boldsymbol{f}$ by the equation :

$$
\tau_{N} f \bar{v}^{2}=\text { Constant }
$$

This is certainly a simplification (Reference 2) and is constructed by combining the Strickler Berg equation relating spontaneous and induced radiation coefficients of a molecule with the expression for oscillator strength $\boldsymbol{f}$ (the intensity/wavelength integration over the absorption band). $\tilde{v}^{2}$ is the square of the weighted, mean fluorescence frequency (here expressed in wavenumbers). The stronger the oscillator strength, the shorter the natural lifetime, and of the many processes competing for the energy of the excited state, fluorescence stakes out a larger share. Thus many dyes are fluorescent, but that doesn't necessarily make them laser active.

\section{Emission Cross-Sections}

There are two emission processes we are interested in; they are the spontaneous (ie. fluorescence) and the induced. In the second a stimulating photon deactivates an excited molecule to produce an additional photon of the same direction, wavelength and phase.

The scientific literature is almost non-existent on molecular emission cross-sections. But, as I stated at the beginning of this talk, we want dyes with low signal saturation fluxes. We gain an understanding of the $\sigma_{\mathrm{e}}$ parameter by measurement, so I would like briefly to take you through my studies on rhodamine 6G (Reference 3).

The aim of the examination is to laser pump the dye hard within the main absorption band and to probe the excited state volume with a weak second beam at different wavelengths to determine loss or gain (Figure 3). It is not a difficult experiment, but it needs to be done carefully and it is time consuming. Schematic of the equipment is shown in Figure 4. There are some experimental points of concern : (1) The excitation beam particularly needs to be uniform, this is achieved by a pinhole mask $\mathbf{P}_{\mathbf{1}}$ over the most uniform part of the beam and gives a tophat excitation profile. (2) The probe beam needs to be concentric and needs to be contained completely within the excited state volume. (3) The probe beam needs to be shorter and needs to be contained completely, time-wise, within the excitation pulse. The pulse-lengths, $6 \mathrm{~ns}$ for

the pump and $2 \mathrm{~ns}$ for the probe (FWHM) are long enough so that we are in the physics regime we want to measure. (4) The dye cell windows are non-parallel and the cell has a small angular offset to avoid amplified fluorescence buildup, ie. spontaneous lasing. (5) The dye concentrations are high enough to give measurable absorptions over a suitable path-length, but 
are not so high as to promote amplified spontaneous emission (ASE). We used about $10^{-4} \mathrm{M}$ concentrations for $1.0 \mathrm{~mm}$ path length. (6) The pump and probe beams are plane-polarized and have crossed polarizations.

What about the results? Figure 5 shows transmission through the dye for increasing pump flux. For the wavelength chosen, although it becomes more transmitting at the stronger fluxes, there is still a weak residual absorption, which we ascribe to excited state absorption. An additional experimental point, (7) we perform our second, probe beam measurements with the pump operating always in this fully saturated condition. Probing in the absorption band is straightforward. In the emission region the amplified probe beam itself deactivates the excited dye, which invalidates our assumption of a fully saturated inversion population. We get around this by (8) carefully extrapolating to small signal gain. My results are plotted in Figure 6 and are combined with earlier, similar measurements by Dolan and Goldschmidt (Reference 4) deeper over the absorption band in Figure 7.

Figure 7 deserves close attention. Depending on the wavelength the dye can be more absorbing, unchanged, or less absorbing in the excited state. The cross-over point from absorption to gain in the $\mathbf{S}_{\mathbf{1}}$ spectrum occurs to the blue of the peak ground-state absorption. It is remarkable that one can pump the dye very hard (at a shorter wavelength) and probe at the absorption maximum and it actually has gain!

I spent about a year doing this measurement and I came up with a result I might have anticipated anyway. The emission is a reflection of the absorption. We already know that the fluorescence is a mirror image, and the theoretical basis for this is because the induced emission must be a refection of the absorption; the spontaneous and induced coefficients are related. The symmetry applies as long as the nuclear configurations of the ground and excited electronic states are similar.

There is a point in doing the experiment however. We can clearly see excited state absorption $\sigma^{*}$ at shorter wavelengths in the rhodamine $6 \mathrm{G}$ spectrum, and the measurements across the emission band are in fact the difference between $\sigma_{e}-\sigma^{*}$ (Figure 3). Our attempts to resolve the $\sigma_{\mathrm{e}}$ and $\sigma^{*}$ components are shown in Figure 8 . The reason rhodamine $6 \mathrm{G}$ is an effective laser dye is because the emission cross-section is much larger than the excited state absorption, and it is this $\sigma_{\mathbf{e}}-\sigma^{*}$ term which should really be considered when defining a dye's signal saturation flux in Equation 2. The condensed aromatic hydrocarbons pyrene, perylene, diphenylanthracene and others are highly fluorescent but are not laser dyes. This must be because they have large excited state absorptions. 


\section{Tumbling of Dye and Solvent Molecules}

Before considering the chemistry there are two further physical concepts we should discuss.

Dye. We have been thinking in terms of conventional spectroscopy up till now. However the dye molecule is not a sphere with equal absorption cross-sections and equal emission crosssections along each of three orthogonal axes. Rather it is rod-shaped with cross-sections $3 \sigma_{p}$ and $3 \sigma_{\mathrm{e}}$ on a coincident axis and this axis rapidly tumbles in solution. The lifetimes of the excited molecules in oscillators and particularly power amplifiers are very short, in the tens of picoseconds, whereas the tumbling time (orientational relaxation time) of rhodamine $6 \mathrm{G}$ in ethanol is 200 to $300 \mathrm{ps}$. Thus the dye has lost its excited state energy before it has time to move, propagation is effectively through a rigid medium. There are a number of consequences in terms of efficiency and in terms of optimum configuration of laser design (Reference 5).

Lets consider the case of polarization. The experiment of Figure 9 applies to the case of rhodamine $6 \mathrm{G}$ in glycerol. Here the orientational relaxation time in the viscous solvent is even longer than the fluorescence decay time. The cell is transversely pumped with the polarization shown and a signal of known polarization is passed through the excited volume. For parallel and perpendicular polarizations the signal comes through amplified, although the perpendicular amplification is less than the parallel. For an injected signal at an angle $\theta$ to the perpendicular axis, the amplified signal is twisted. The signal projects on the two axes and these are amplified differently.

Solvent. The solvent molecules themselves undergo rapid tumbling and this is important when they form the environment about the chromophore. The act of light absorption is extremely rapid and the neighboring solvent molecules do not accommodate immediately to the new excited dipole. A simple spectral experiment with a special solvent is shown in Figure 10. Rhodamine $6 \mathrm{G}$ in methyl isobutyrate behaves as in most other solvents; the fluorescence spectrum, the quantum yield and the fluorescence decay time are independent of the excitation wavelength. Compare this using the chemically related plastic medium Lucite (the second formula in Figure 11). The absorption spectrum is unchanged, yet the fluorescence spectrum is blue-shifted; moreover this shift depends on the excitation wavelength. Here, light absorption is the same for liquid and plastic. The excited molecules in the plastic however are still constrained in their ground-state environments, they have not reached and never will reach the 'solvent equilibrium.' Moreover, there are many, different excited dye/solvent centers in the 
plastic and we access particular centers according to the excitation wavelength. We call this an inhomogeneous population.

In the amplifiers, the turnover time ( $70 \mathrm{ps})$ of the excited dye population at the exit faces is shorter than the Debye relaxation time $\tau_{\mathrm{D}}$ for ethanol ( $94 \mathrm{ps}$ ), a rough measure of single, solvent molecule rotation. Thus even this more rapid, solvent molecule rotation phenomenon also comes into play.

Earlier in this talk I said I would not be lecturing on customary principles of dye behavior. There is another reason. I don't think the equations are correct anyway!

\section{DYE CHEMISTRY}

\section{Dye Classes}

Structures having large oscillator strengths include the extended conjugated double bond systems shown in Figure 12, the polyenes and polymethines. The long-wavelength absorption bands contain the majority of the absorption intensity in the whole of the accessible electronic spectrum. There is no other oscillator to compete with the main chromophore that could interfere in the way of excited state absorption. About $95 \%$ of laser dyes can be fitted within these categories, admittedly rather loosely. This is not essential however. A large oscillator strength, a long fluorescence decay time and a weak excited state absorption in the region of the mirror image fluorescence, permitting low pump and signal saturation fluxes in Equations (1) and (2), are really what are needed.

Incorporating the structures of Figure 12 in a rigid, planar framework optimizes fluorescence quantum yields. The typical approach for the polyenes is to make use of para substituted polyphenyl chains as shown for the scintillator dyes in Figure 13. This is not ideal. Ortho hydrogens, as shown in Figure 14, distort planarity in the ground state. In the excited state however, bond readjustment separates the hydrogens, the structure is strictly planar and fluorescent. The absorption spectrum of p-terphenyl is broad and structureless, whereas the fluorescence shows multiple peaks. A feature an organic chemist meets in synthesizing laser dyes is depicted also in Figure 14. A large structure is built up from smaller structures, which are themselves fluorescent and laser dyes, albeit at shorter wavelengths. Like terphenyl, sexiphenyl is a laser dye and there are other examples I shall describe later.

The way a cyanine graduates to a rhodamine dye is shown in Figure 15. Further ring constraint of the terminal nitrogen atoms produces $100 \%$ quantum yield materials. The 
structure III shown is in fact a pyronine, not rhodamine, but is spectrally very close. The pendant phenyl group of the rhodamine is there for the convenience of synthesis, simply phthalic anhydride with a m-aminophenol; but it also stabilizes the molecule. Replacement of the central $\mathrm{C}-\mathrm{H}$ group by nitrogen gives the oxazine dyes. The oxonol dye class of Figure 12 likewise graduates to the fluoresceins. The merocyanine dye class includes such structures as the 7-aminocoumarins and DCM.

The polyenes and merocyanines exhibit alternation in bond length and undergo extensive nuclear reorganization in the excited state. Both absorption and emission processes activate many vibrational modes. The symmetric cyanines and oxonols on the other hand, have uniform bond structures and on excitation experience little change in equilibrium geometry. Thus for the same oscillator strength, the cyanines and oxonols exhibit sharp, intense absorptions and fluorescences with small Stokes shifts, whereas the polyenes and merocyanines show broad, weaker spectra. Absorption wavelength increases linearly with increasing chain length for the cyanines (and oxonols) but only asymptotically to a limit for the polyenes and merocyanines.

\section{Blue-Green Dyes}

Our aims for the Navy blue-green lasing dye program were optimum conversion efficiency about the $480 \mathrm{~nm}$ wavelength, along with high dye stability under flashlamp excitation. The structures we made are shown in Figures 16 and 17. From a stability point of view we aimed to remove the 4-methyl group of a known dye 7-diethylamino-4-methyl-coumarin, inhibit photodimerization across an unprotected coumarin 3,4 position and fully alkylate the amino group. For conversion efficiency we ring-constrained the amino group for optimizing fluorescence quantum yield. In the first stage of this work (Reference 6) the most efficient and most stable dye was the one labelled C8F in Figure 16, but unfortunately the peak wavelength had red-shifted to $520 \mathrm{~nm}$. The second stage of this project (Reference 7) was done in conjunction with another program and more intermediates became available. The dye labelled $\mathrm{AC} 2 \mathrm{~F}$ in Figure 17 had optimum conversion efficiency and stability at the right wavelength. Many of these dyes are available commercially today.

\section{Violet Dyes}

The interest in violet dyes occurred in two projects. The first was a requirement for efficient, stable flashlamp pumped dyes operating about $380-400 \mathrm{~nm}$. A second, later interest 
was a comparison of dyes for a two-step " $400 \mathrm{~nm}$ " versus three-step “600 nm" ionization process for uranium.

Polyene class, scintillator dyes were known to operate at $380-400 \mathrm{~nm}$, but it was hoped that substitution of the quite efficient coumarin dyes could shift their operation into this region. Figure 18 shows the fluorescence maxima for substituted 7-aminocoumarin and 7aminoquinolone dyes; they are blue-shifted but not far enough. Figure 19 introduces 8-aza substitution and we do reach the target. Another idea tried is represented in Figure 20. The anion of glutaconic anydride $\mathrm{C}$ is the monocyclic extension of the efficient bicyclic 7 hydroxycoumarin B and efficient tricyclic fluorescein dye A. One could envision a whole series of monocyclic dyes, but the approach was a failure. The two lower compounds shown did lase (the second was an intermediate in making aza-coumarins), but typically the quantum yields were low $\sim 1 \%$ (Reference 8 ). The outcome of this study was that we came up with a dye about as good as a known dialkoxy-quaterphenyl - $i e$. a substituted polyene dye. An interesting point is that although air (or oxygen) improved performance and stability for the merocyanine it diminished them for the polyene. Since then better polyene dyes have been developed.

The ionization potential of uranium is about $200 \mathrm{~nm}$. The interest here was the comparison of tunable dye processes at around $400 \mathrm{~nm}$ and $600 \mathrm{~nm}$, apart from the pump lasers - xenon chloride at $308 \mathrm{~nm}$ and copper vapor at $510.6 \mathrm{~nm}$. Absorption and fluorescence of typical three step (rhodamines - derived cyanines) and two step (scintillators - derived polyene) dyes are shown in Figure 21. Although the azaquinolones lase at the $400 \mathrm{~nm}$ wavelength, they in fact have absorption minima at the pump $308 \mathrm{~nm}$ and are less efficient. The absorption and emission cross-sections of Figure 21 turn out to be about the same. On the other hand, as Equation 7 predicts, the radiative lifetime is shorter for the $400 \mathrm{~nm}$ dye than for the $600 \mathrm{~nm}$. Also the violet photon is more energetic than the red so that saturation fluxes are about ten times higher for the violet dye than for the red, if we also take fluorescence radiation trapping into account. For the same pump and signal fluxes in a dye amplifier (measured in $\mathrm{MW} / \mathrm{cm}^{2}$ ) the violet dye is much less efficient than the reu. Also the violet dye stability is about two orders of magnitude less than the red. Thus the energies of the excited singlet states $53 \mathrm{kcal}$. for the red and $80 \mathrm{kcal}$. for the violet may be compared to the carbon-carbon single bond energy of $59 \mathrm{kcal}$. Moreover, as discussed earlier, oxygen has to be degassed from solution. Not that a process using violet dyes can't be developed; it requires much more chemical work though than for the red. 


\section{$\underline{\text { Red Dyes }}$}

Rhodamine $6 \mathrm{G}$ is also known in the dye trade as Basic Red 1. Several years ago it was selling worldwide at about 150 tons a year. Thus for red laser dyes we are off to a good start.

We have had an interest in a number of rhodamines. Some of the twenty to thirty new dyes we have chosen to make are shown in Figures 22 and 23. Our interests have been in optimizing fluorescence quantum yields by ring constraint, shifting wavelengths by substitution, and esterification of the carboxyl group for stability and unambiguity of dye structure.

Making the dyes is generally straightforward; the ring-constrained m-aminophenols precursors however require some attention. My first attempts at 1,2,3,4-tetrahydro-7hydroxyquinoline derivatives relied on 7-hydroxyquinoline made by the Skraup reaction Figure 24. This is a messy, poor-yield (about 6\%) reaction not suitable for industrial scale-up. The original 1892 Badische Anilin und Sodafabrik patent for making rhodamine 6G is shown in Figure 25. N-Monoethyl o-toluidine was sulfonated, then alkali fused to N-monoethyltoluidine-4-phenol. We developed a similar process for 1-methyl-1,2,3,4-tetrahydro-7hydroxyquinoline as shown in Figure 26 (Reference 9) and we indeed used this method, scaled up, for making dyes. The alkali fusion reaction however could not be made to work for the ring constrained free $\mathrm{N}-\mathrm{H}$ aminophenols, and for these we developed alternate paths as shown in Figures 27 and 28 (Reference 10). The second we had found from a similar preparation of indoline dyes.

These dyes are only moderately stable $\left(\mathbf{Q}_{\mathbf{M}}\right.$ about $\left.10^{-6}\right)$ compared with customary industrial standards, but they can be made to work very well for a Laser Isotope Separation Plant. For our thousand gallon dye amplifier loops and multi-kilowatt average power of pump and signal beams, a typical system deteriorates about $10 \%$ over a month of continuous day and night operation. It becomes a matter of monitoring, automatic feed and bleed to maintain acceptable performance, and recovery of the alcohol for reuse by distillation at a later stage. We expect to be able to make riore stable dyes, but this is a secondary issue compared with optimizing conversion efficiency.

\section{Deep Red, Infra-Red Dyes}

This is an area where I think existing dye technology can be markedly improved. There is not a strong motivation to do it however because of introduction of the effective, tunable titanium sapphire laser that operates over the $700-1000 \mathrm{~nm}$ region. 
The rhodamines can be shifted to the red by adding substituents although the materials are not chemically stable. The oxazines are an example of substituting a $\mathrm{C}-\mathrm{H}$ group of the chromophore by nitrogen, although the performance is somewhat inferior to the rhodamines and the wavelength does not go beyond $800 \mathrm{~nm}$. A merocyanine dye, DCM (formula shown later in Figure 31), has a large Stokes shift and broad tuning range, although it doesn't perform much beyond $730 \mathrm{~nm}$.

The present, most effective deep-red, infra-red compounds however are the "Styryl" dyes, examples are shown in Figure 29. They have large Stokes shifts and broad tuning ranges when pumped, for example, by doubled neodymium in oscillators, but with performances inferior to the rhodamines. They are long chain-length, unsymmetrical, derived cyanines. They have unconstrained, conjugated double bond systems and it is remarkable that they are laser dyes at all for the fluorescence quantum yields are typically less than 5\% Returning to Equation 7 however, longer wavelength dyes permit a marked increase in the $\tau_{N} f$ product, and, other factors being equal, we should expect a marked decrease in pump and signal saturation fluxes. The best lasing dyes that exist should in fact be in the deep-red, near infra-red region!

How can we improve performance? Most of these dyes show fluorescence enhancement in glycerol. This is customary behavior for low quantum yield dyes in this viscous solvent and supports the argument that making these structures rigid will optimize performance. A potentially optimally fluorescing molecule such as I proposed in Figure 30, may be thought of as a rigid Pyridine 2. This is not simple chemistry and some other, incomplete attempts at making rigid cyanine structures have been unsuccessful. An idea we examined for extending the chain length by a method that is successful for the polyenes, is shown for the dye DCM in Figure 31. To an extent this works, particularly for the right solvents. Thus DCM lasing optimally at $660 \mathrm{~nm}$ is shifted out to $750 \mathrm{~nm}$, although the performance is not better than Pyridine 2. By this technique a good dye (DCM) becomes a mediocre red-shifted dye, whereas the mediocre styryl dyes produce no new active laser materials at all. An interesting point - the intermediates used in the synthesis (Figure 32) are again laser dyes, about as good as the aminocoumarins in the blue.

Another feature which we have not had to contend with for the rhodamines is absorption of the solvent. This arises from C-H vibrational overtones, the sixth overtone at about $635 \mathrm{~nm}$, the fifth at $745 \mathrm{~nm}$, the fourth at $910 \mathrm{~nm}$ and the third at $1190 \mathrm{~nm}$, with absorption intensities in the approximate ratios $1: 6: 80: 850$. Figure 33 shows $10 \mathrm{~cm}$ path absorptions for a liquid hydrocarbon for the sixth and fifth overtones. Similarly Figure 34 compares protium and deuterium oxide absorption arising from $\mathrm{O}-\mathrm{H}$ overtones. Fluorescence degradation may be considered as a particular case of non-radiative energy transfer occurring from the singlet 
excited dye to the solvent higher vibrational states. The transfer rate depends on the acceptor's oscillator strength and spectral overlap. It increases at longer wavelengths $\left(v^{-4}\right)$, and it is sensitive to the average transfer distance $\left(\mathbf{r}^{-6}\right)$, decreasing rapidly for greater separation. As expected we find enhanced fluorescence in solvents low in $\mathrm{C}$-H composition eg. chloroform. Substituents increasing molecular separation $\left(\mathrm{Cl}, \mathrm{CF}_{3}\right)$ also improve fluorescence dichloroethane, chlorobenzene, trifluorotoluene. Aromatic solvents themselves appear to fit into this category also - benzonitrile, methylbenzoate. It seems that the aromatic $\pi$-electron system hinders close intermolecular approach. For example a good solvent giving quite efficient performance for $\mathrm{CW}$ dyes in the near infra-red is phenoxyethanol (Reference 11).

\section{MISCELLANEOUS}

\section{Dye Molecule Tweaking}

The oscillator tuning curve for rhodamine 6G is shown in Figure 35. When compared with the fluorescence spectrum in Figure 2, or, better still, the induced emission spectrum in Figure 6 , the peak wavelength of the tuning curve is red-shifted from the emission maximum. The reason is that the dye is not $100 \%$ inverted, the tail absorption interferes with lasing and causes a displacement to the red. The position of the tuning peak depends on concentration - a lower concentration causes a shift towards the blue; and on the balance between pump and signal fields - a stronger pump flux also causes a shift to the blue.

The dye amplifier shown in Figure 1 in fact represents a series of larger and larger single-...s pass amplifiers. As a signal propagates along a chain to bigger amplifiers, the media are laser pumped progressively harder, whereas the dye concentrations are reduced in step according to amplifier size. Thus for the same dye the peak of the tuning curve for each amplifier is shifted progressively to the blue along the chain. If we want to operate at the peak of the tuning curve for maximum efficiency, then optimum performance requires slightly shifted dyes in each amplifier along the chain. Some of the dye structure options we choose have been shown earlier in Figures 22 and 23.

\section{Dipyyrylmethine Dyes}

A number of boron difluoride substituted dipyrrylmethine dyes (also known as BODIPY dyes) have become available recently and representative structures are shown in Figure 36. 
Certainly the one on the top-right shows a $20 \%$ performance improvement in an oscillator compared with rhodamine dyes under $510.6 \mathrm{~nm}$ pumping.

With the formulas drawn as shown, it is possible, with a little imagination, to derive them from a cyanine parent structure. The spectra are similar to the rhodamines - intense, sharp absorptions, although the oscillator strengths are smaller, about 0.3 vs 0.5 . Because of the rigid structures the fluorescence Stokes shifts are very small, about $10 \mathrm{~nm}$, vs about $20 \mathrm{~nm}$ for

the rhodamines. A point of interest, the dilute solution fluorescence decay time in alcohol, 6.03 ns, is about $30 \%$ longer than expected from the oscillator strength and 0.83 fluorescence quantum yield. This is why they are good laser dyes, the saturation fluxes are lower.

Now for some criticisms. Heavy alkylation of the molecules is necessary chemically. Pyrroles and dipyrrylmethines, from which the molecules are synthesized, are reactive and the alkyl groups inhibit polymerization to a degree. This means the structures are crowded and can be distorted. Unlike the rhodamines, where quantum yields close to $100 \%$ are regularly achieved, the fluorescence, although strong is weaker $\left(\mathbf{Q}_{\mathbf{M}} 0.7\right.$ to 1.0 , Reference 12) and varies in an erratic manner. Not all the "best" dipyrrylmethine dyes are better than the "best" rhodamines. Also the Stokes shifts vary.

An important point, the compounds are unstable. A solution stored in $95 \%$ ethanol for thirteen weeks under ambient laboratory conditions had only $16 \%$ of the original dye remaining and showed partial hydrolysis of the B-F bonds. We need dyes with the same chromophore but improved stability.

\section{Water Dyes}

Water as a laser dye solvent medium has advantages over organic solutions. It has a high thermal capacity ( 1.00 cal.deg. ${ }^{-1} \mathrm{ml}^{-1}$ vs 0.45 for ethanol); it has a low refractive index change with temperature $\left(10^{-4} \mathrm{deg}^{-1}\right.$ vs $4 \times 10^{-4}$ for ethanol) and it has a high thermal conductivity $\left(0.6 \times 10^{-2} \mathrm{watt} / \mathrm{cm}^{0} \mathrm{C}\right.$ vs $0.18 \times 10^{-2}$ for ethanol). These are useful both in terms of safety and in terms of superior optical properties of the medium.

An approach that we have not seriously tried is dye dispersion in aqueous soap solutions. Rhodamine dyes equilibrate between the soap micelles and water solution and the soluble fraction becomes subject to aggregation and fluorescence quenching. The dispersions have long term stability problems and are likely to lead to window burning at the glass/medium interface.

Our approach has been to make water soluble dyes. Water has exceptional, almost unique properties. It is a liquid with extensive, strong internal hydrogen bonds, and organic materials 
(including most dyes) do not dissolve in it. The requirement for a high fluorescence quantum yield is a much stricter requirement than mere water solubility though. Strong fluorescence requires monomolecular dispersion, not aggregation. Water solubility of an organic molecule is enhanced by a structure which enters into hydrogen bonding or which capitalizes on the high dielectric constant, ie. an anion, cation or a strong dipole. A class of rhodamine derived anion dyes we have made are shown in Figure 37 - Reference 13.

The dyes perform well as long as the concentrations are below $10^{-3} \mathrm{M}$, at which point fluorescence quenching (darkening) starts to occur, presumably the result of molecular aggregation. Amplifier performance is quite efficient and stable whereas their output from an oscillator is long pulse (150 ns FWHM) and clean mode quality. The dye on the top-left shows an oscillator performance in water identical to rhodamine $6 \mathrm{G}$ in alcohol, although the peak output is down $10 \%$. The dye at bottom-right is a failure, it doesn't lase in water. All four sulfonate groups are needed on the molecule for adequate water solubilty. The dye at bottomleft also was not very successful. Fluorescence of the green-pumped oscillator solution was clearly weaker than other candidates. This rearrangement of the methyl groups appears to cause crowding and distortion of the molecule, lowering fluorescence. Also aggregation for this dye is severe.

However long term operation and storage gave problems due to bacterial growth in the medium. The dyes are not only non-toxic, they are nutritious! This was solved by use of a disinfectant. Another problem was window burning on the laser output window. Most probably the latter was caused by rust particle displacement, the filter was found to be heavily contaminated for example. Window burning for alcohol dyes diminished on prolonged operation, where the solvent volume was continuously swept through $0.1 \mu$ filters. Water is a chemically more aggressive and biologically more fertile solvent than ethanol. For water dyes more attention is needed to loop cleaning, sterile preparation and disinfection. 


\section{REFERENCES}

1) P.R. Hammond and R. Nelson, "Radiation trapping in a laser dye medium," $\underline{E E E ~ J . ~}$ Quant. Elect., 1980, Vol. QE-16, p 1161.

2) J.B. Birks, "Photophysics of aromatic molecules," Wiley-Interscience, New York, 1970.

3) P.R. Hammond, "Spectra of the lowest excited singlet states of rhodamine $6 \mathrm{G}$ and rhodamine B," IEEE J. Quant. Elect., 1979, Vol. QE-15, p 624; "Comparison of experimental and theoretical excited state spectra for rhodamine 6G," ibid., 1980, Vol. QE-16, p 1157.

4) G. Dolan and C.R. Goldschmidt, "A new method for absolute absorption crosssection measurements : Rhodamine $6 \mathrm{G}$ excited singlet-singlet absorption spectrum," Chem. Phys. Lett., 1976, Vol. 39, p 320.

5) P.R. Hammond, "Performance of laser dye solutions under high signal fluxes : An analysis of signal propagation and excited state energy extraction in mobile and rigid media," J. Appl. Phys., 1985, Vol. 57, p 4916.

6) E.J. Schimitschek, J.A. Trias, P.R. Hammond and R.L. Atkins, "Laser performance and stability of fluorinated coumarin dyes," Opt. Commun., 1974, Vol. 11, p 352 .

7) E.J. Schimitschek, J.A. Trias, P.R. Hammond, R.A. Henry and R.L. Atkins, "New laser dyes with blue-green emission," Opt. Commun., 1976, Vol. 16, p 313.

8) P.R. Hammond et al., "Search for efficient, near UV lasing dyes," Parts I, II and III, Appl. Phys., 1975, Vol. 8, p 311 and 315; 1976, Vol. 9, p 67.

9) P.R. Hammond, "Preparation of certain m-aminophenols and the use thereof for preparation of laser dyes," US 4,622,400; $11^{\text {th }}$ November, 1986.

10) G.F. Field and P.R. Hammond, "Method for preparation of 1,2,3,4-tetrahydro-7hydroxyquinoline," US 5,283,336; $1^{\text {st }}$ February, 1994.

11) P.R. Hammond and D. Cooke, "Continuous wave dye lasers in the DCM region," Appl. Opt., 1992, Vol. 31, p 7095.

12) J.H. Boyer, A.M. Haag, G. Sathyamoorthi, M.L. Soong and K. Thangaraj, "Pyrromethine- $\mathrm{BF}_{2}$ complexes as laser dyes. 2," Heteroatom Chemistry, 1993, Vol. 4, p 39.

13) P.R. Hammond, J.F. Feeman and G.F. Field, "Water soluble laser dyes," US $5,792,389 ; 11^{\text {th }}$ August, 1998. 


\section{FIGURE CAPTIONS}

1) Atomic vapor laser isotope separation.

2) Absorption and fluorescence spectra of rhodamine 6G in ethanol.

3) Energy level scheme for two photon absorption and emission in a laser dye.

4) Equipment schematic for measurement of dye excited state absorption.

5) Saturable absorption of rhodamine 6G.

6) Excited state measurements of rhodamine 6G.

7) Ground and excited state spectra of rhodamine 6G.

8) Resolution of emission and excited state absorption cross-sections for rhodamine $6 \mathrm{G}$.

9) Polarization twisting in a rhodamine 6G/glycerol dye amplifier.

10) Absorption and fluorescence spectra of rhodamine $6 \mathrm{G}$ in liquid and glass solutions.

11) Chemical structure of methyl isobutyrate and Lucite.

12) Polyene/polymethine dye classes.

13) Polyene dyes.

14) Bond distortion in polyphenols. Dye synthesis from components.

15) Rhodamine structure derivation from a cyanine dye.

16) Blue-green laser dyes $I$.

17) Blue-green laser dyes $\mathbb{I}$.

18) Violet dyes, coumarins and quinolones.

19) Violet dyes, azacoumarins and azaquinolones.

20) Violet dyes, monocyclics.

21) Absorption and fluorescence spectra for two-step and three-step dyes.

22) Rhodamine dyes I.

23) Rhodamine dyes II.

24) Aminophenol intermediatis via the Skraup reaction.

25) BASF 1892 patent for rhodamine $6 \mathrm{G}$.

26) Alkali fusion route to $\mathrm{N}$-methyl-hydroxy-tetrahydroquinoline.

27) Boron hydride route to hydroxy-tetrahydroquinoline.

28) Phophoric acid hydrolysis route to hydroxy-tetrahydroquinoline.

29) Styryl dyes.

30) Hypothetical synthesis of a "rigid" Pyridine 2.

31) Laser dye DCM and extended DCM.

32) Intermediates for making red-shifted dyes. 
33) C-H overtone spectra.

34) O-H overtone spectra.

35) Absorption and oscillator tuning curves of rhodamine $6 \mathrm{G}$ in ethanol.

36) Dipyrrylmethine dyes.

37) Water soluble rhodamine dyes. 


\section{The basic AVLIS systems}

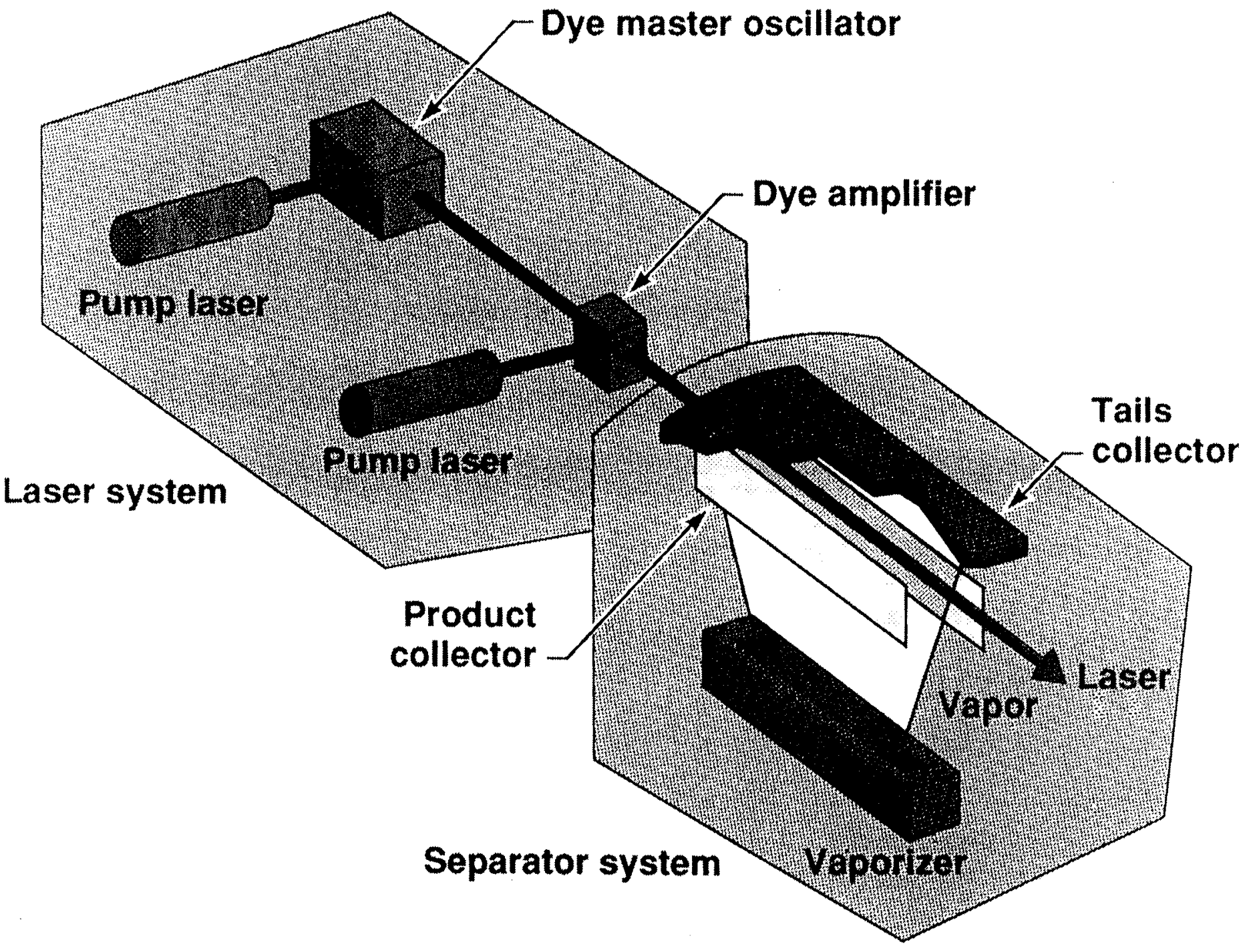




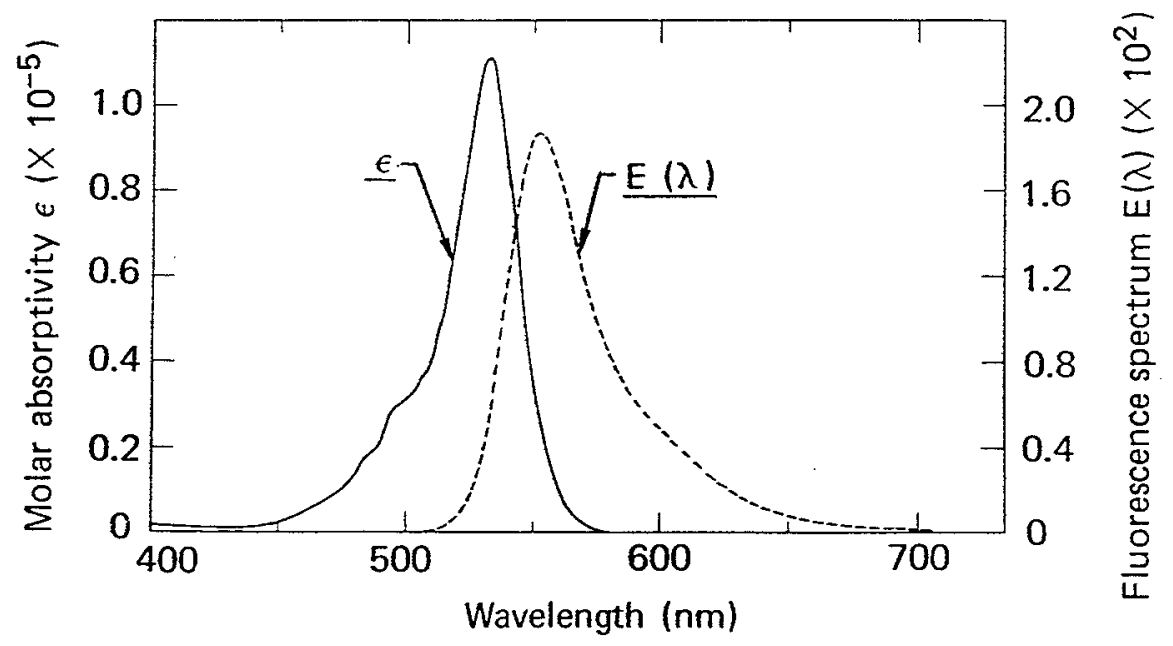

Figure 2 


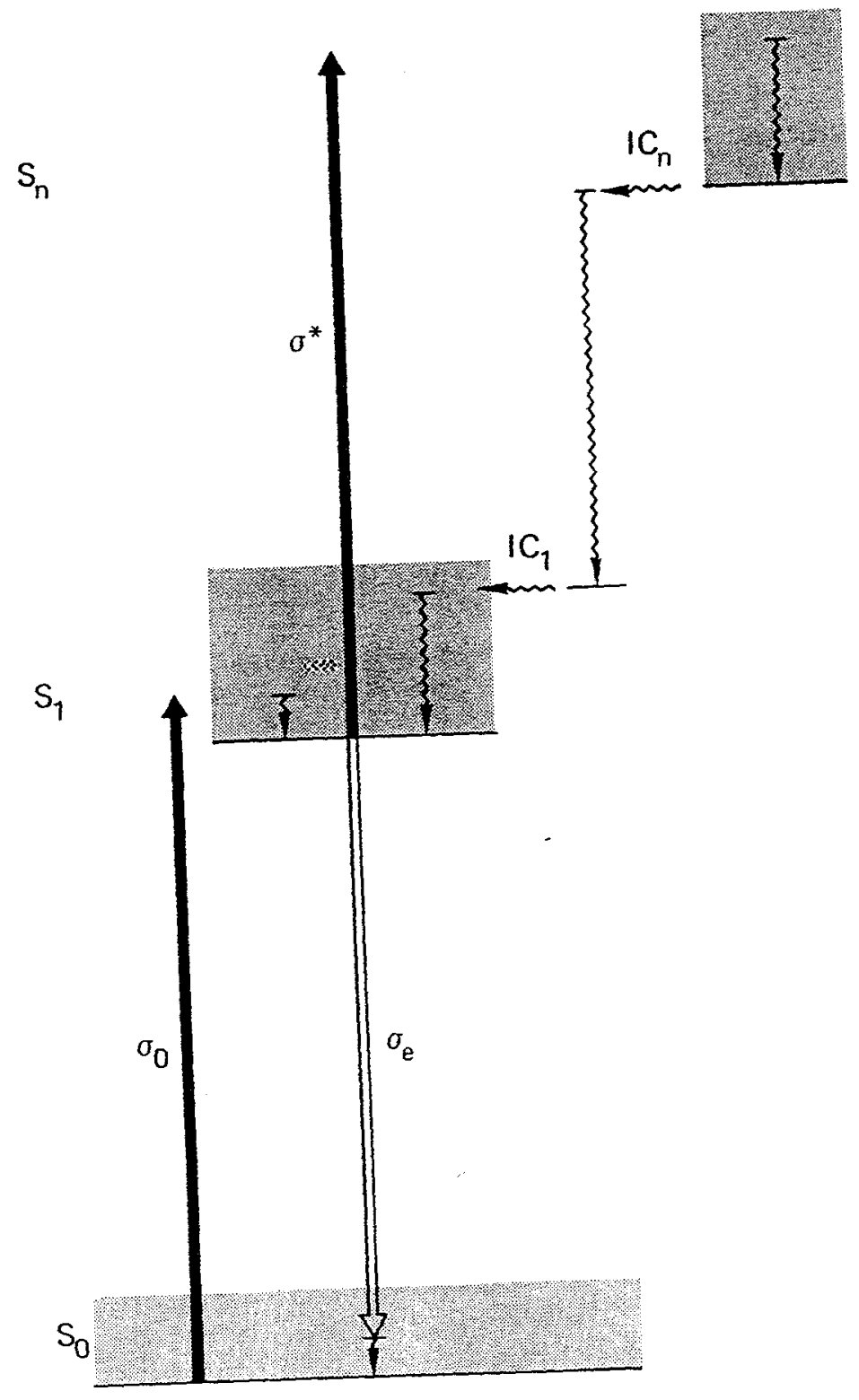

Figure 3 


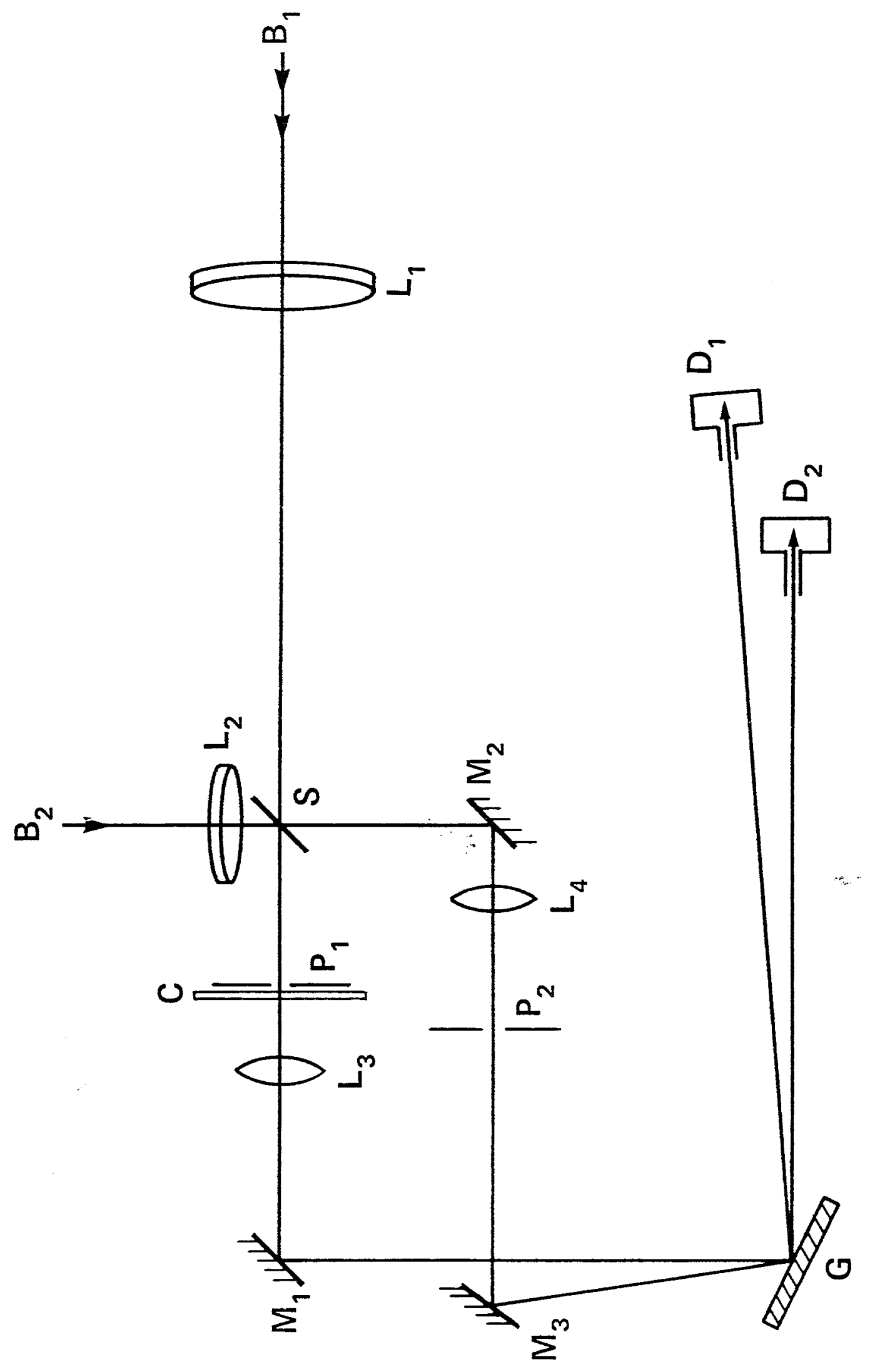

Figure 4 


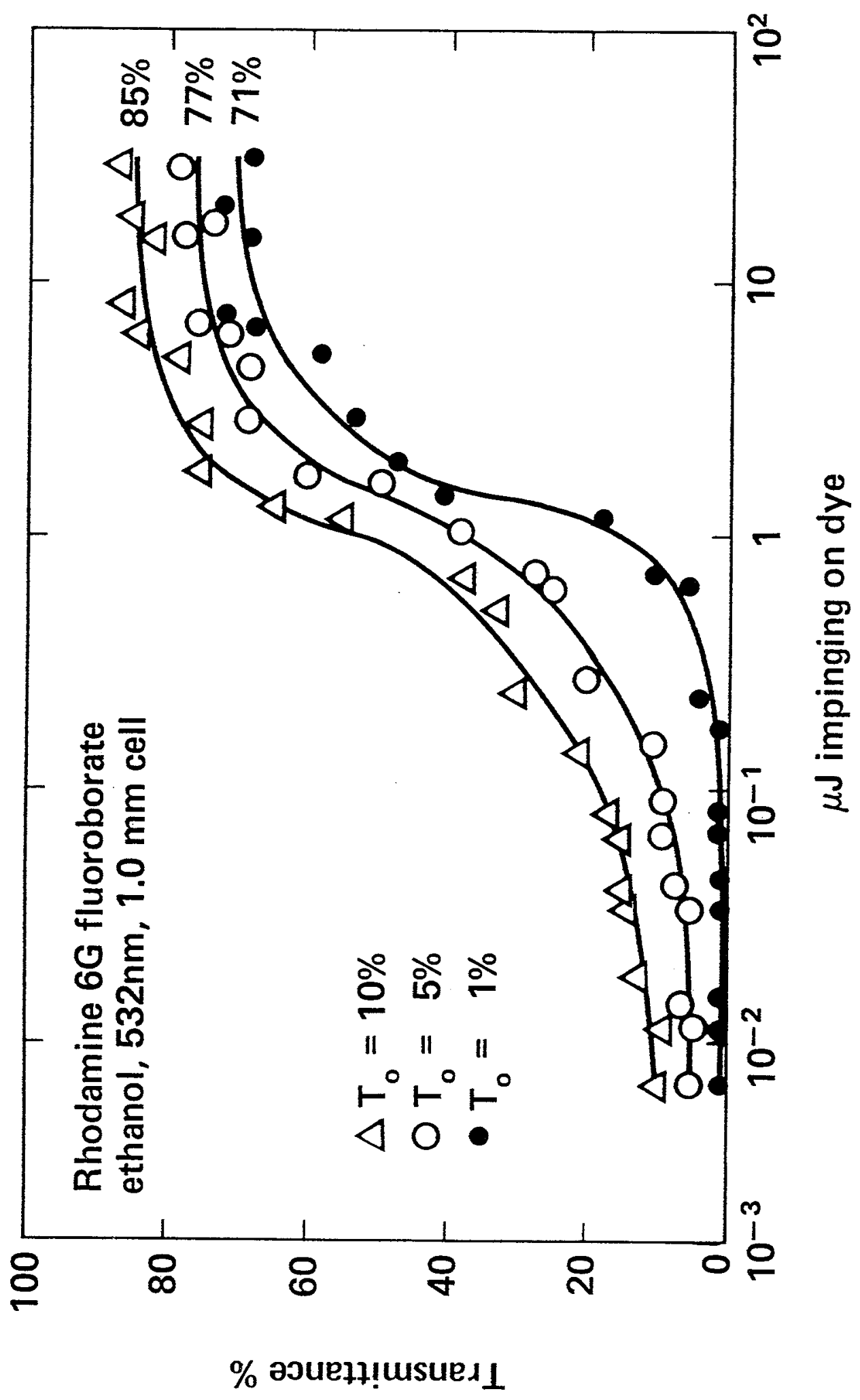

Figure 5 


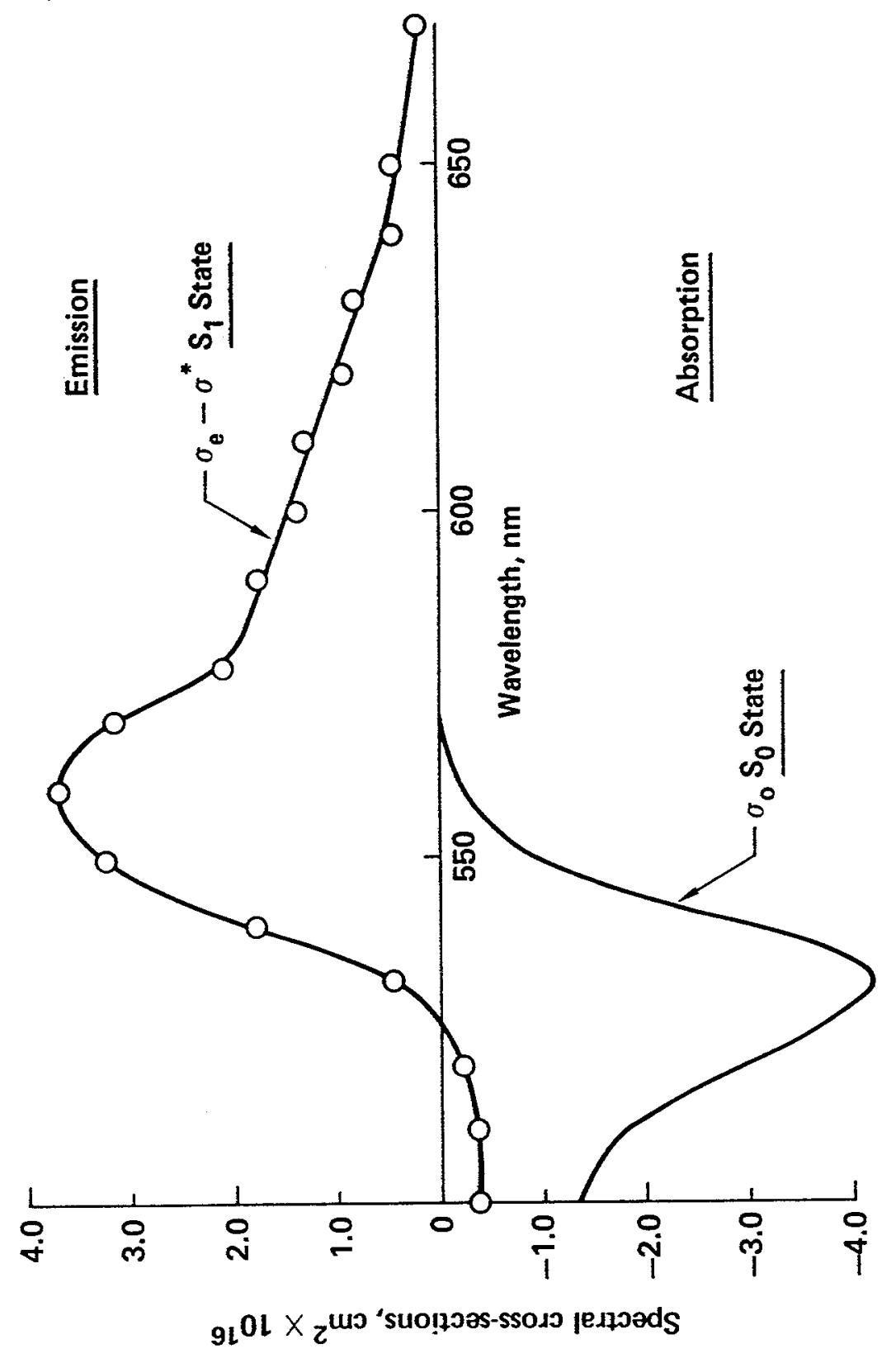

Figure 6 


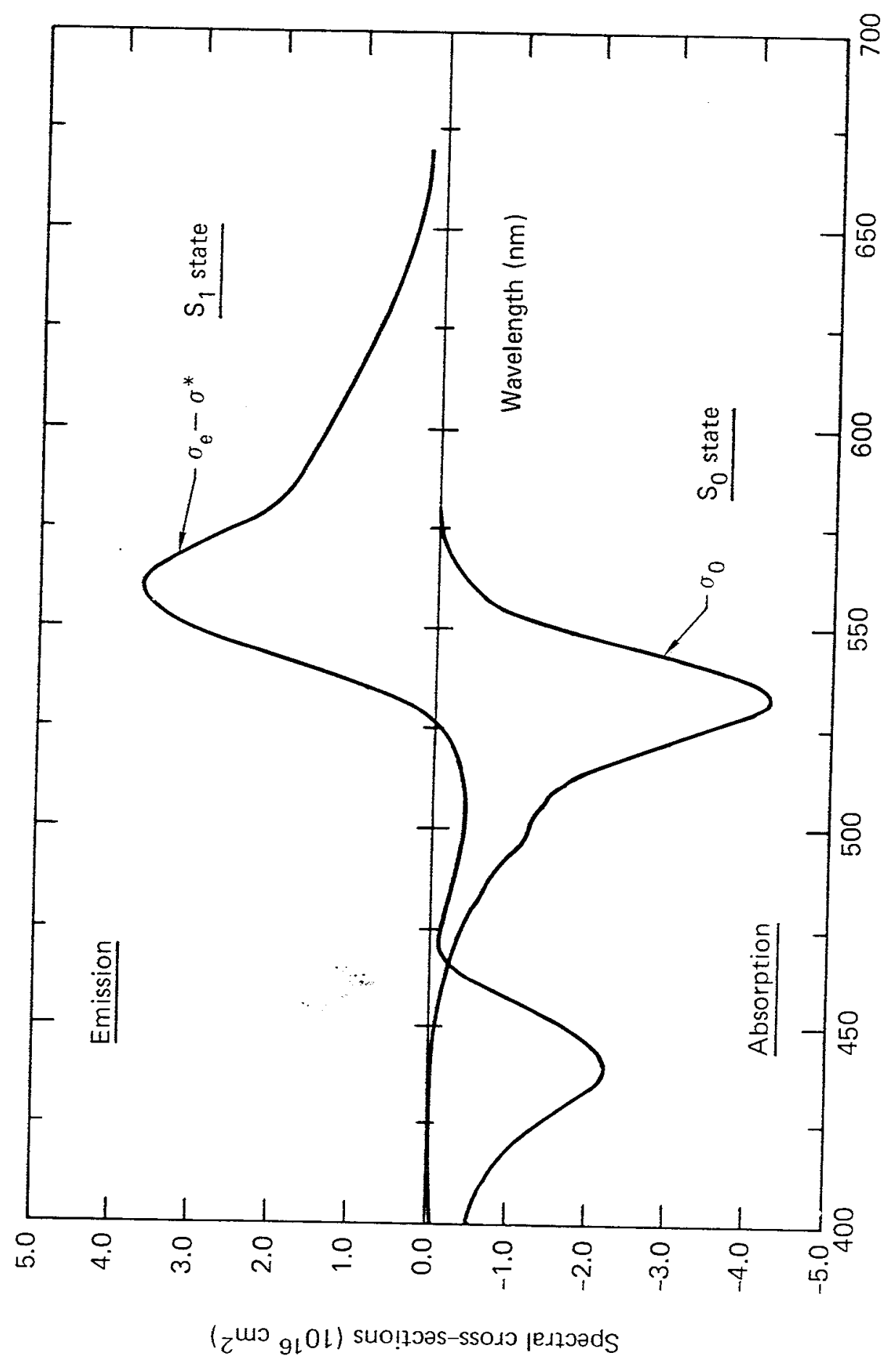

Figure 7 


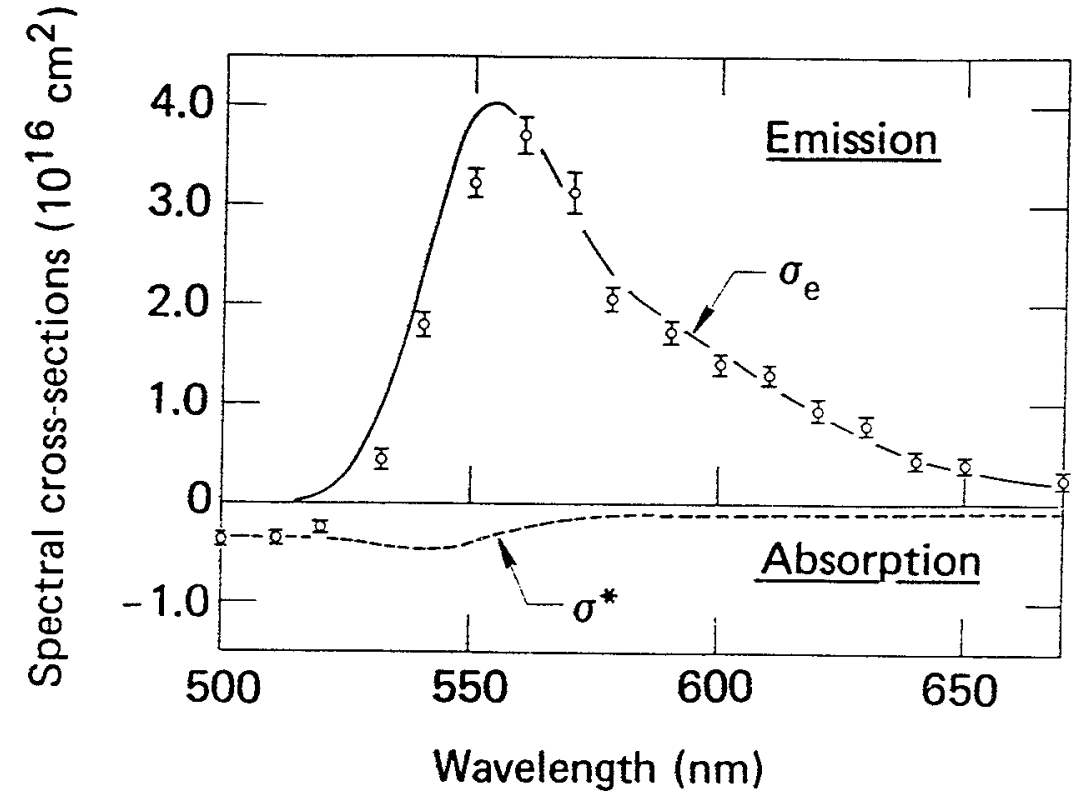

Figure 8 


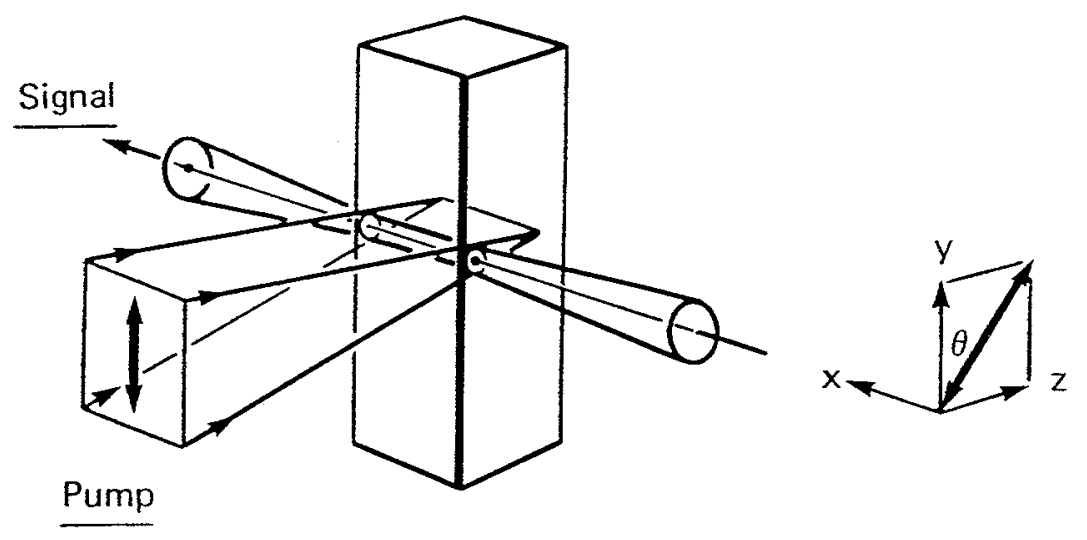

Figure 9 


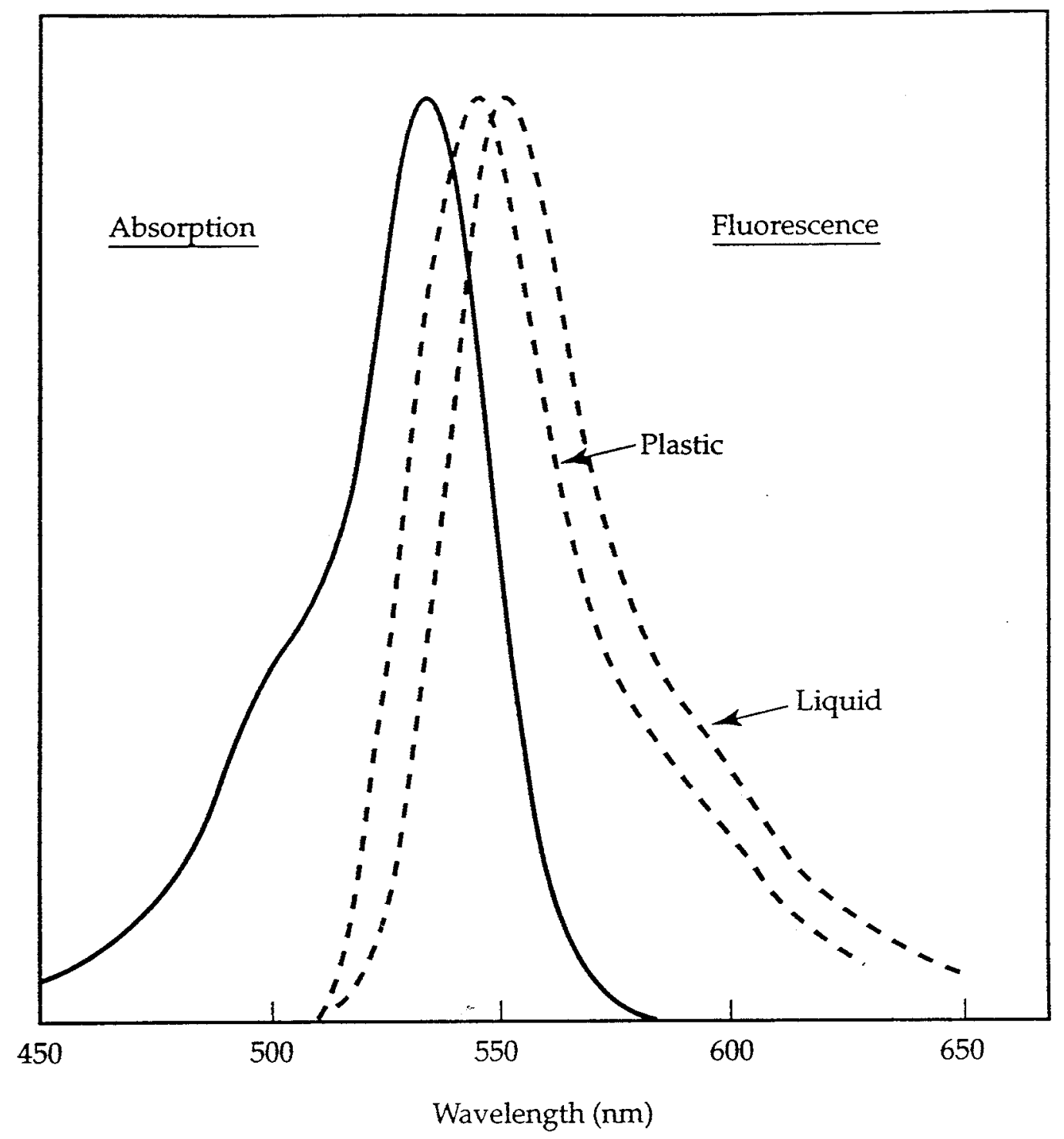

Figure 10 

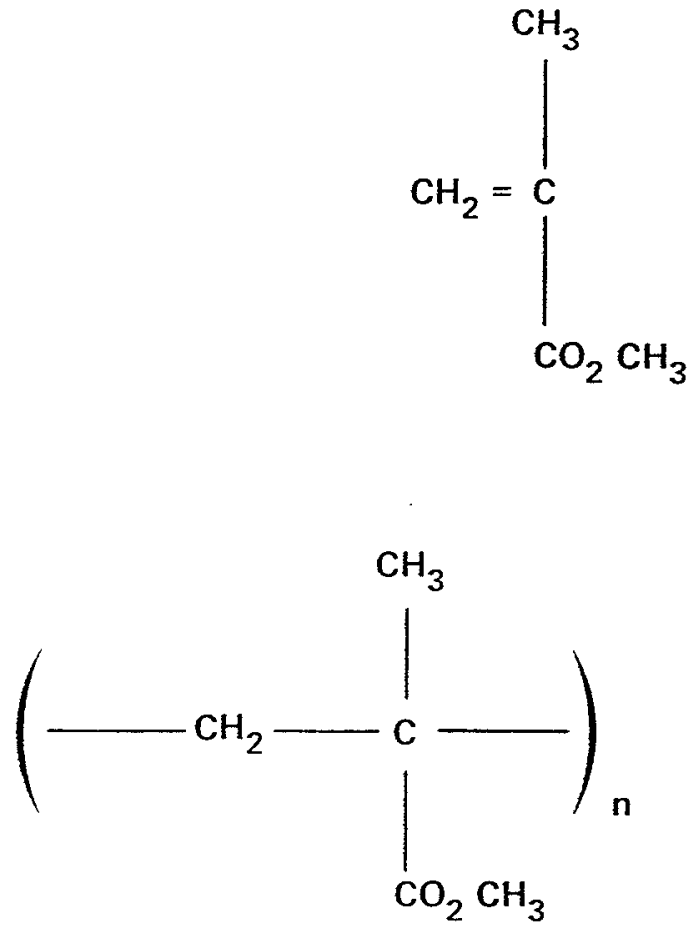

II

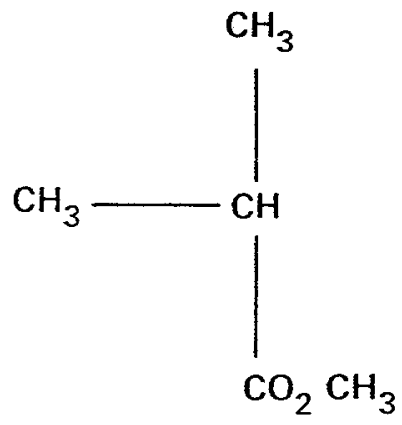

Figure 11 
I Polyene dyes

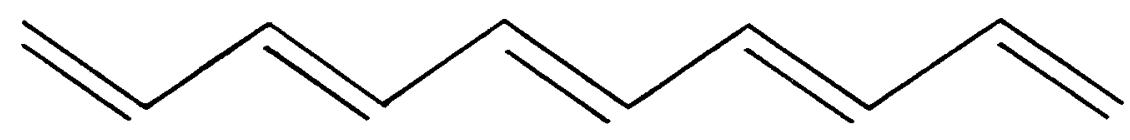

II Polymethine dyes

(a) Cyanines

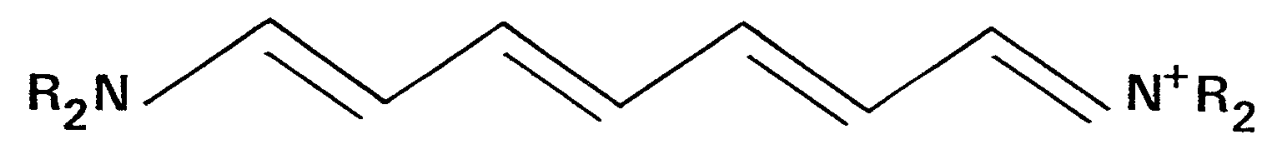

(b) Merocyanines<smiles>[R2]NC=CC=CC=CC=O</smiles>

(c) Oxonols<smiles>O=CC=CC=CC=C[O-]</smiles> 


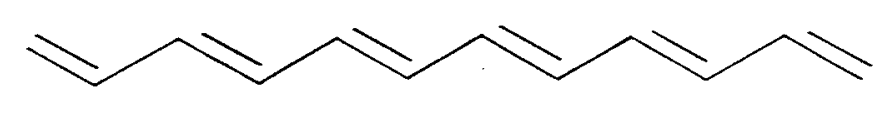

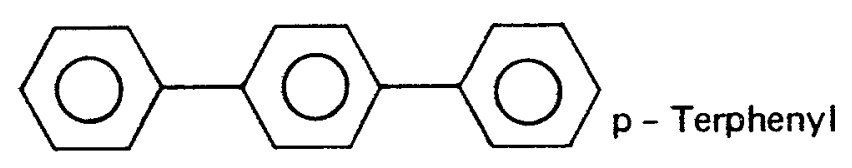
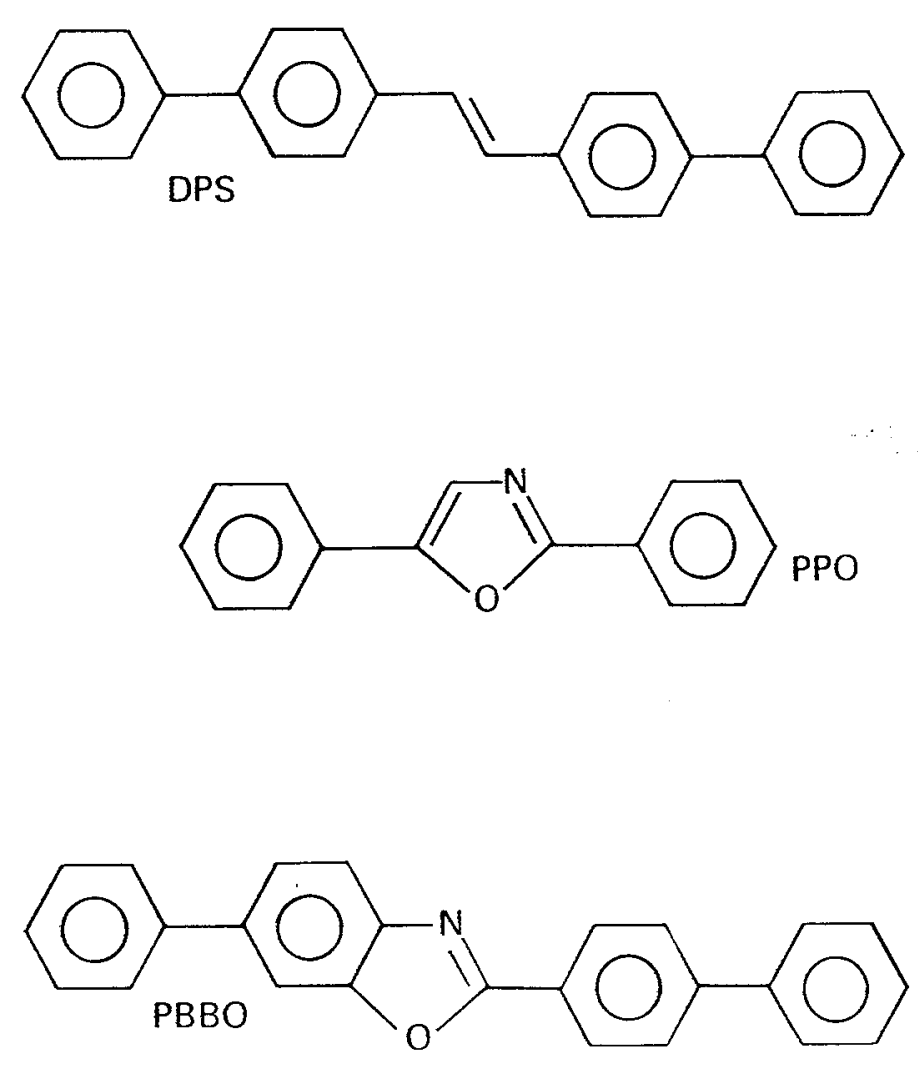

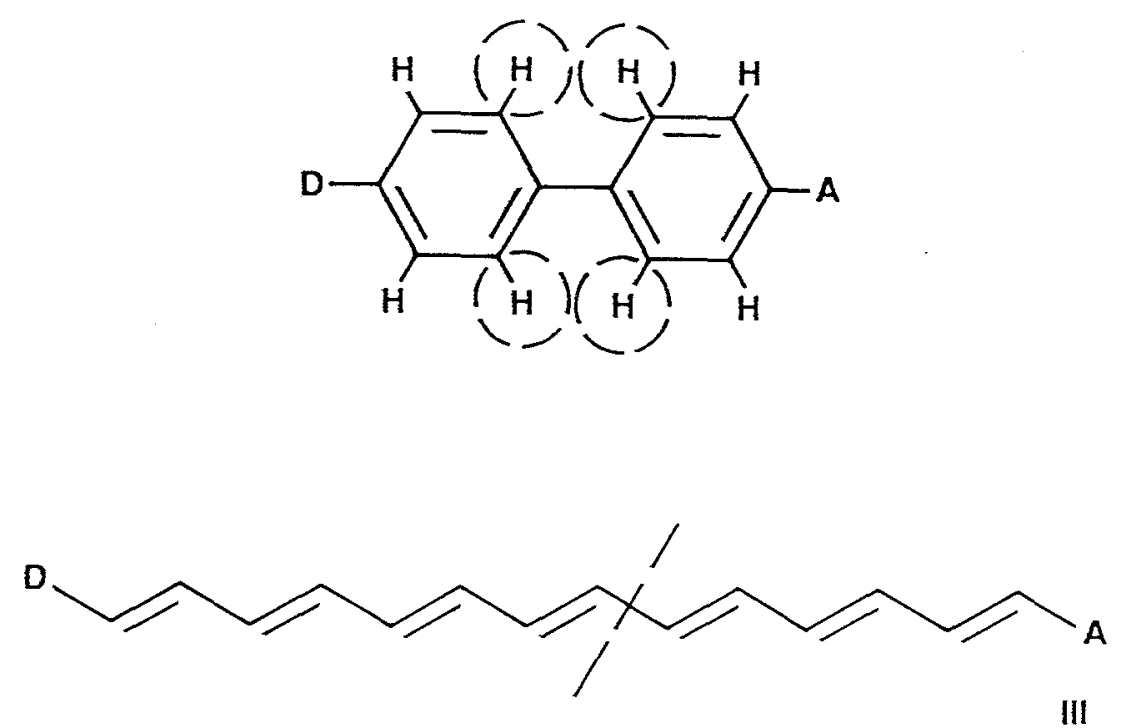

Synthesis

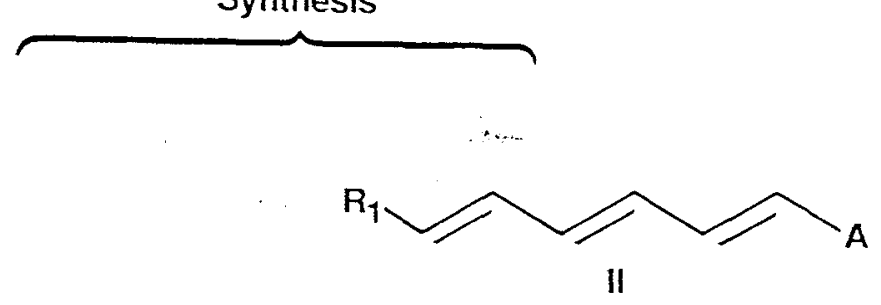

疗

Figure 14 

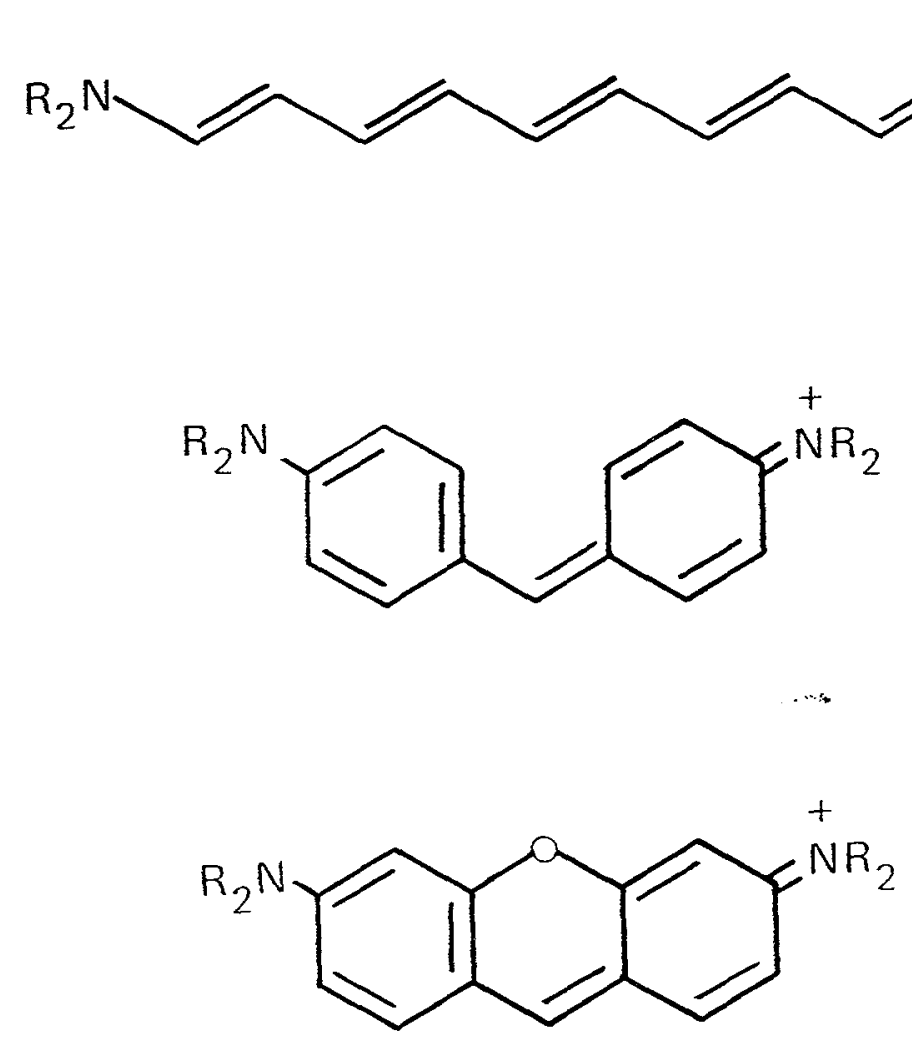
<smiles>CCCCCCN(CC)c1ccc2c(c1)O[C@H](O)C=C2C(C)(C)C</smiles><smiles>CC(C)(C)c1cc2c(cc3c(=O)oc(=O)cc1-3)NCCC2</smiles>

C4F<smiles>O=c1cc(C(F)(F)F)c2ccc(O)cc2o1</smiles>

CTF<smiles></smiles>

C2F<smiles>C[C@@H](O)Oc1c2ccc(C(C)(F)F)c1C=CC1=C2NCCC1</smiles>

C5F<smiles>Cc1cc(=O)oc2cc3c(cc12)CCCN3C</smiles>

CBF<smiles></smiles>

C3F<smiles>CC(C)(C)c1cc(=O)oc2c3c4c(cc12)CCCN4CCC3</smiles>

C6F<smiles>CN1CCCc2c1ccc1c(C(C)(F)F)cc(=O)oc21</smiles>

C9F 


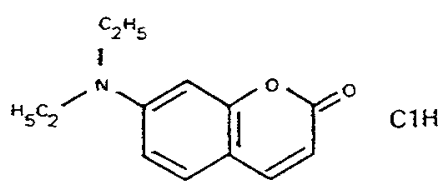<smiles>CC(C)(C)c1cc(=O)oc2nc(N3CCOCC3)ccc12</smiles><smiles>CN(C)c1ccc2ccc(=O)oc2c1</smiles><smiles>CC1CCN(C)c2nc3oc(=O)cc(C(F)(F)F)c3cc21</smiles><smiles></smiles><smiles>Nc1ccc2c(C(F)(F)F)cc(=O)[nH]c2c1</smiles><smiles>CN(C)c1ccc2c(C(F)(F)F)cc(=O)n(C)c2c1</smiles><smiles>O=c1ccc2cc3c(cc2o1)NCCC3</smiles><smiles>C[C@H]1N(C)c2cc3[nH]c(=O)cc(C(F)(F)F)c3cc2C1(C)C</smiles><smiles>O=c1ccc2cc3c4c(c2o1)CCCN4CCC3</smiles><smiles>CC1N(C)c2cc3c(cc2C1(C)C)c(C(F)(F)F)cc(=O)n3C</smiles><smiles>CN1CCCc2cc3ccc(=O)oc3cc21</smiles><smiles>CN(C)c1ccc2c(C(F)(F)F)cc(=O)n(C)c2n1</smiles>

AQIF 


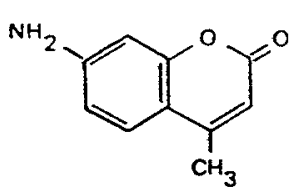

A $429 \mathrm{NM}$

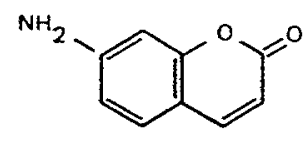

B $439 \mathrm{NM}$

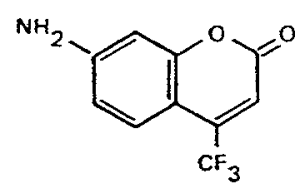

C $484 \mathrm{NM}$

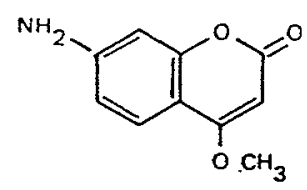

D 405 NM

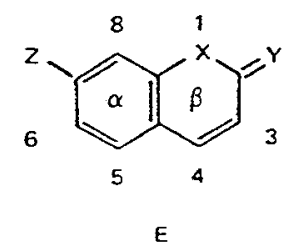<smiles>Nc1ccc2ccc(O)nc2c1</smiles>

F<smiles>Nc1ccc2ccc(=O)[nH]c2c1</smiles>

G<smiles>Cc1cc(=O)n(C)c2cc(N(C)C)ccc12</smiles>

H 415 NM

$1420 \mathrm{NM}$

J $472 \mathrm{NM}$

K $396 \mathrm{NM}$<smiles>Cc1cc(=O)oc2c3c4c(cc12)CCCN4CCC3</smiles>

1474 NM<smiles>O=c1ccc2cc3c4c(c2o1)CCCN4CCC3</smiles>

M 481 NM<smiles>O=c1cc(C(F)(F)F)c2cc3c4c(c2o1)CCCN4CCC3</smiles>

N $536 \mathrm{NM}$<smiles>O=c1ccc2c(C(F)(F)F)c3c4c(c2o1)CCCN4CCC3</smiles>

O $482 \mathrm{NM}$ 

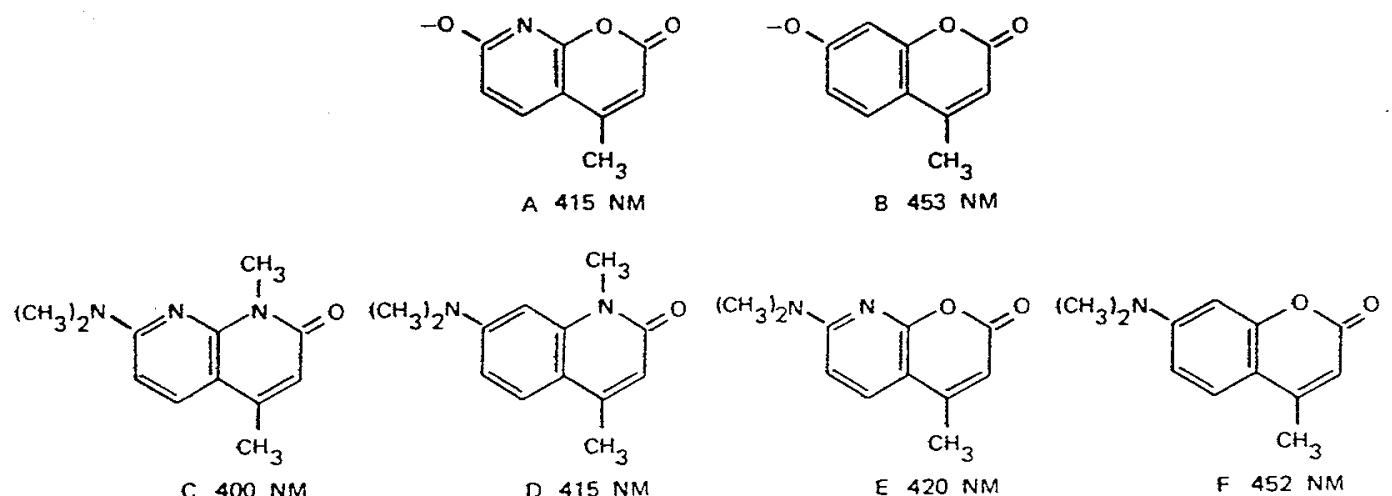

C $400 \mathrm{NM}$

D $415 \mathrm{NM}$

E $420 \mathrm{NM}$

F $452 \mathrm{NM}$
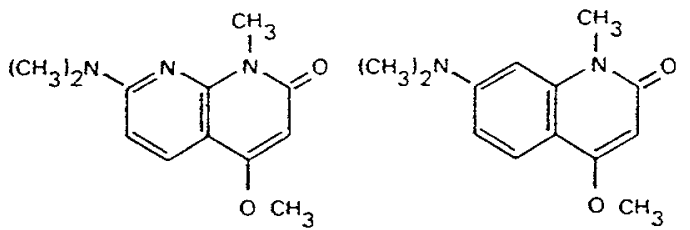

G 383 NM

H 396 NM
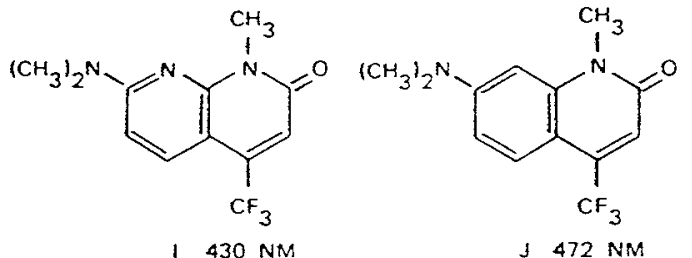

$1430 \mathrm{NM}$

I $472 \mathrm{NM}$ 


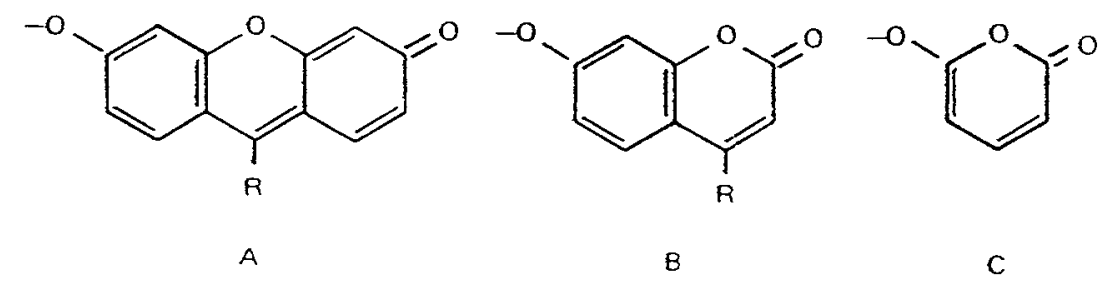

Fig. 1. Oxygen bridged cyclic oxonol dyes

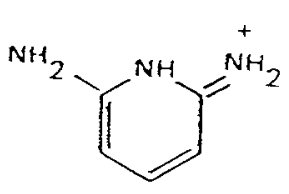

A 395 NM

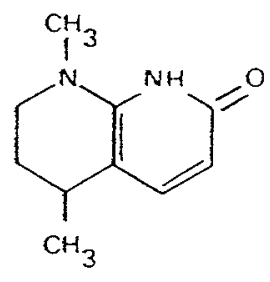

C $413 \mathrm{NM}$ 


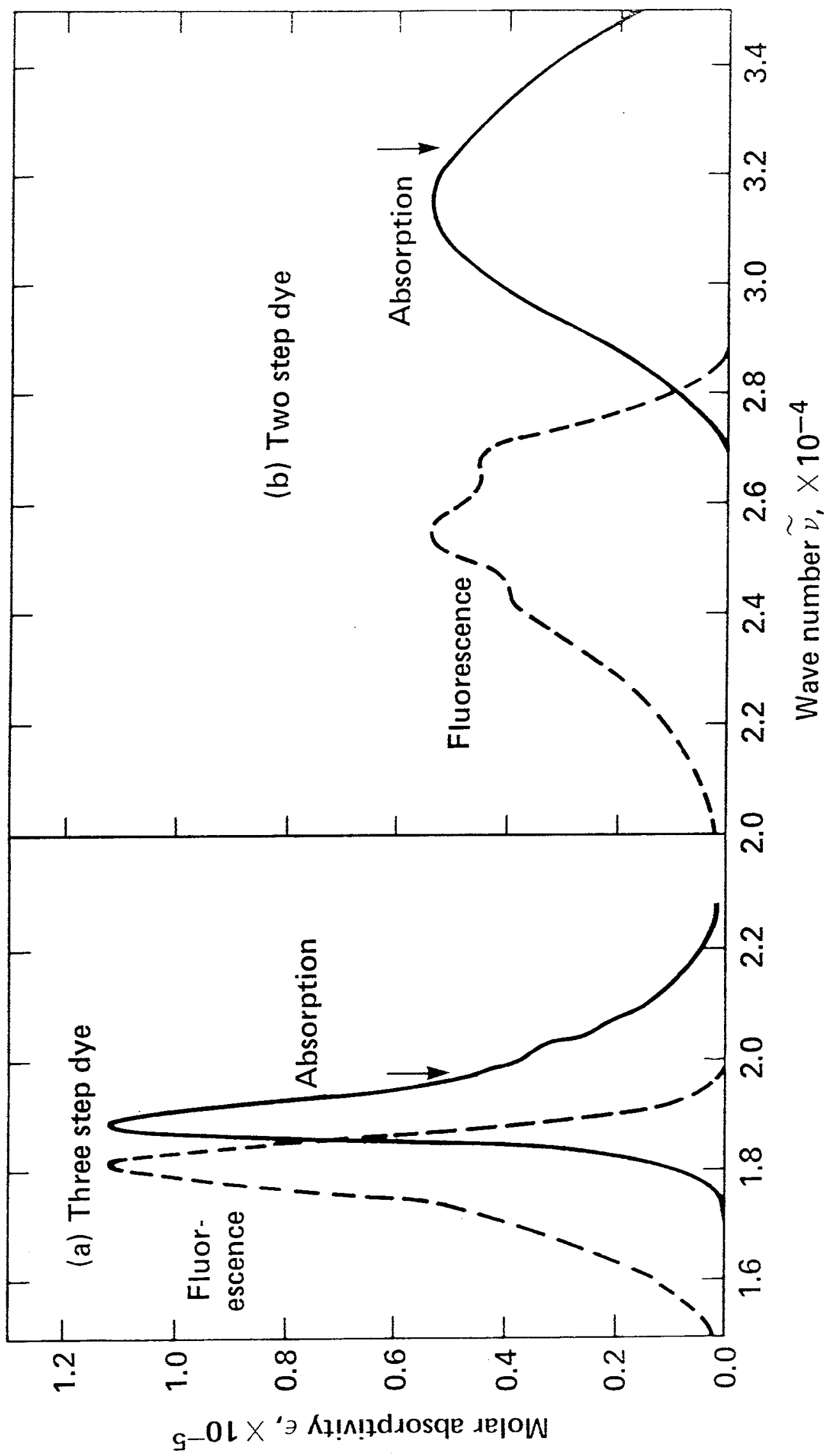

Figure 21 

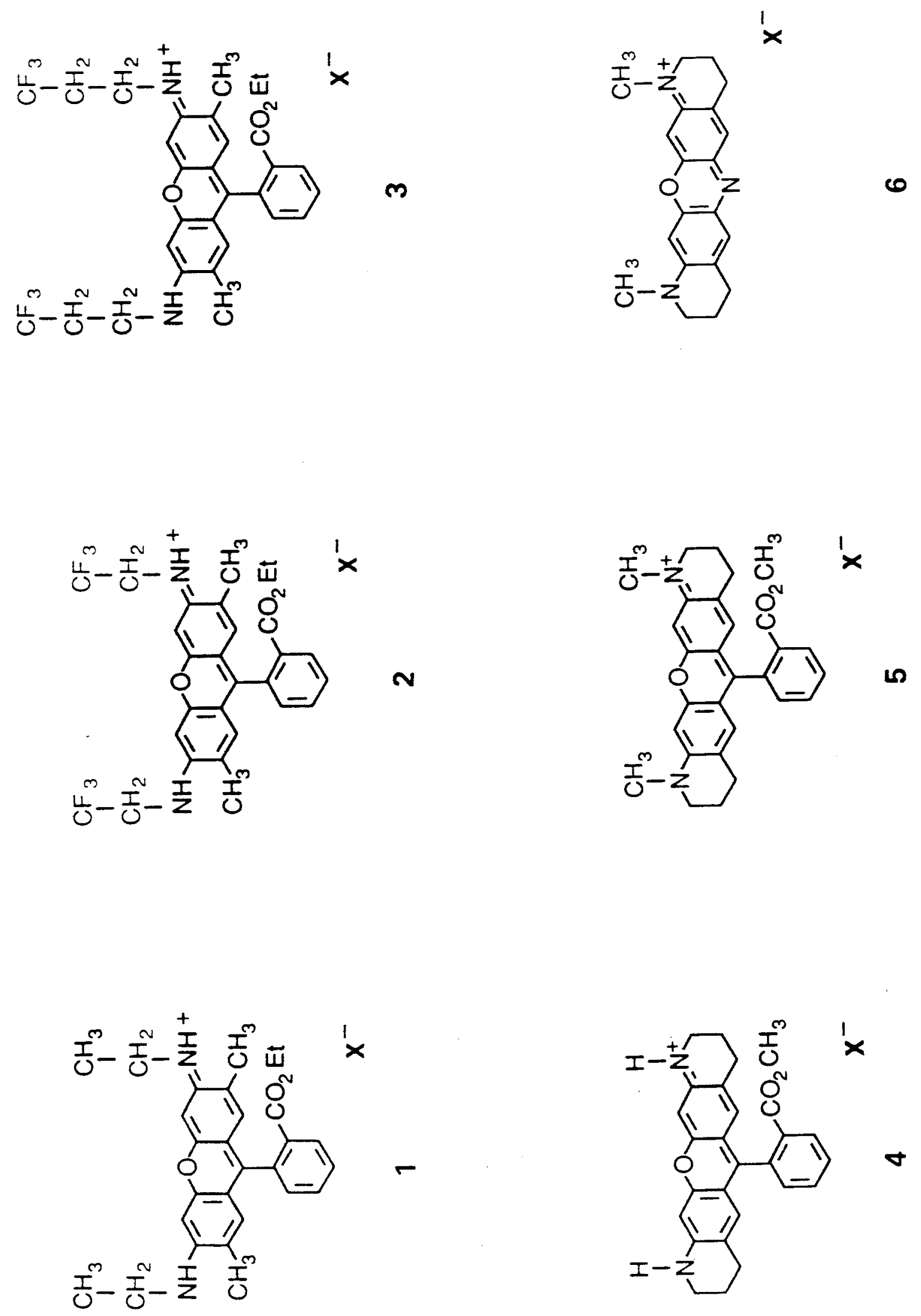

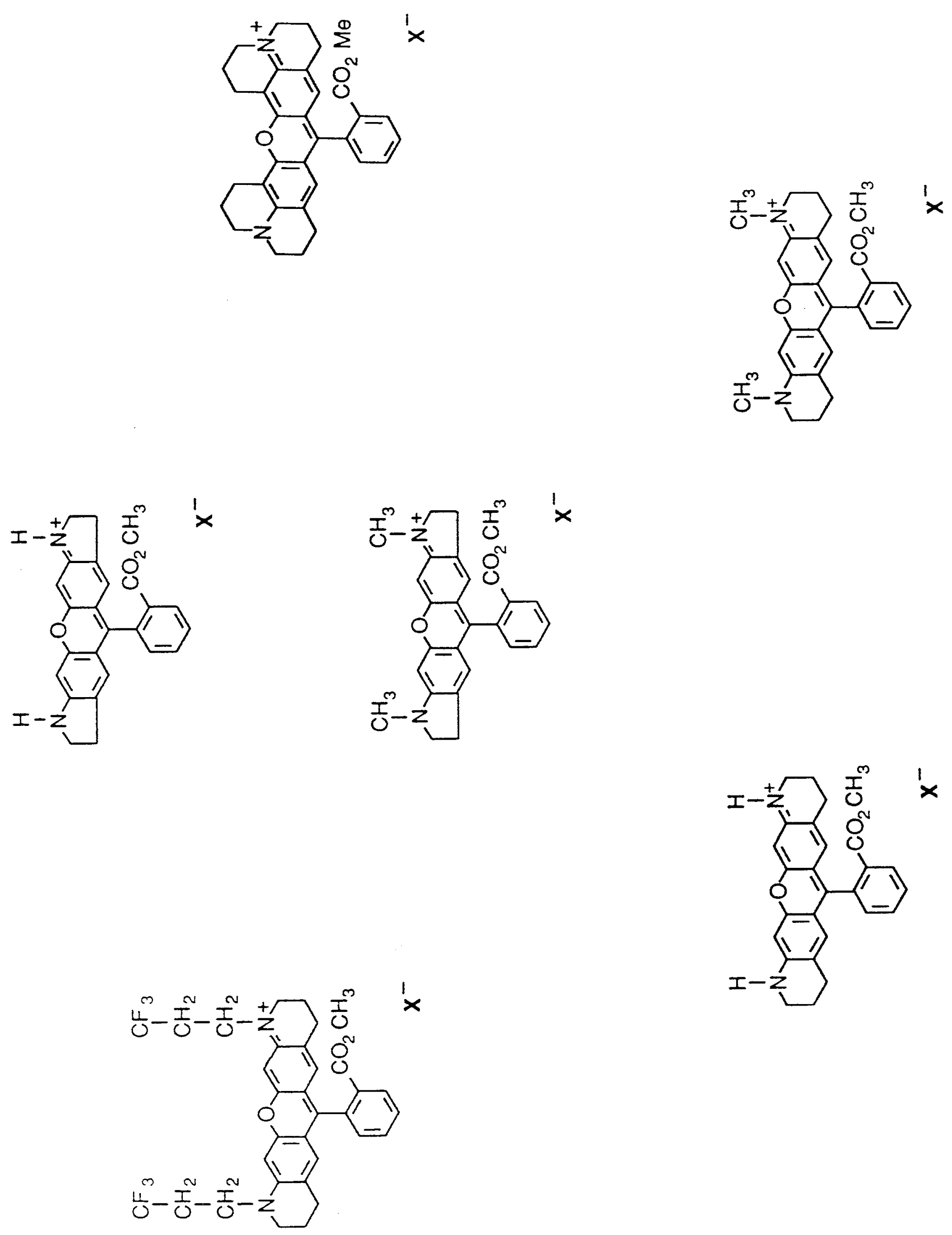

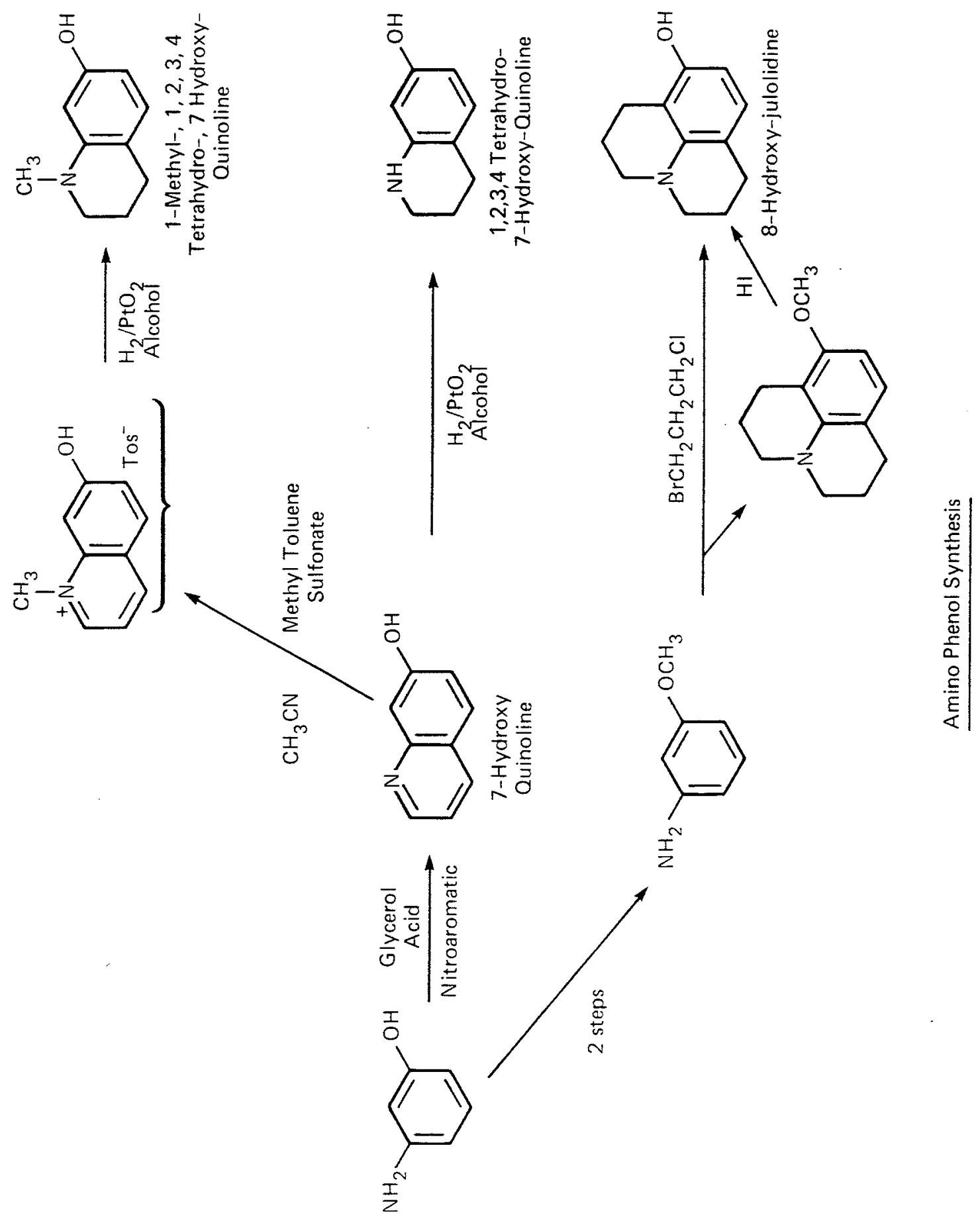

$I^{N}$ 

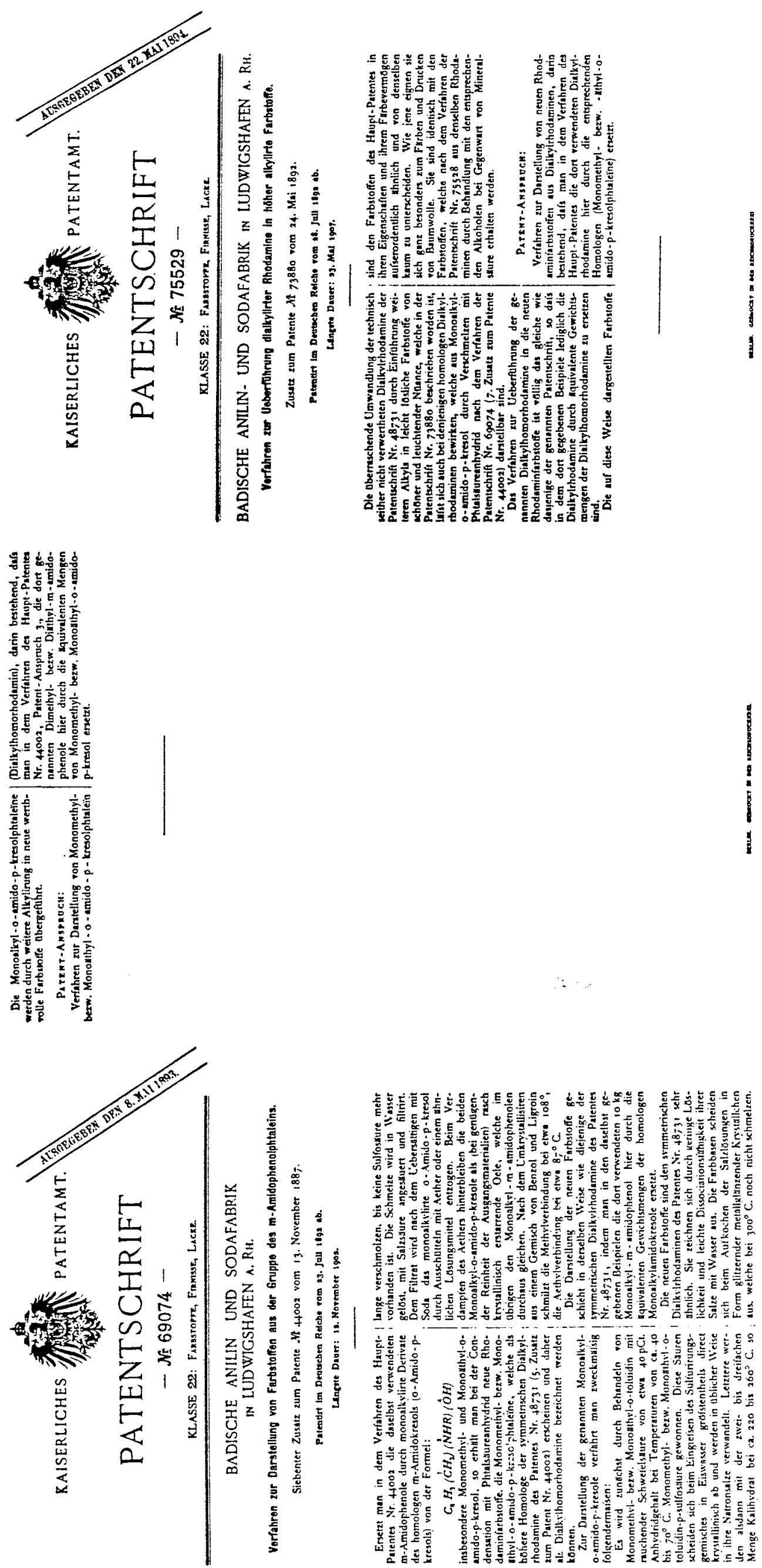


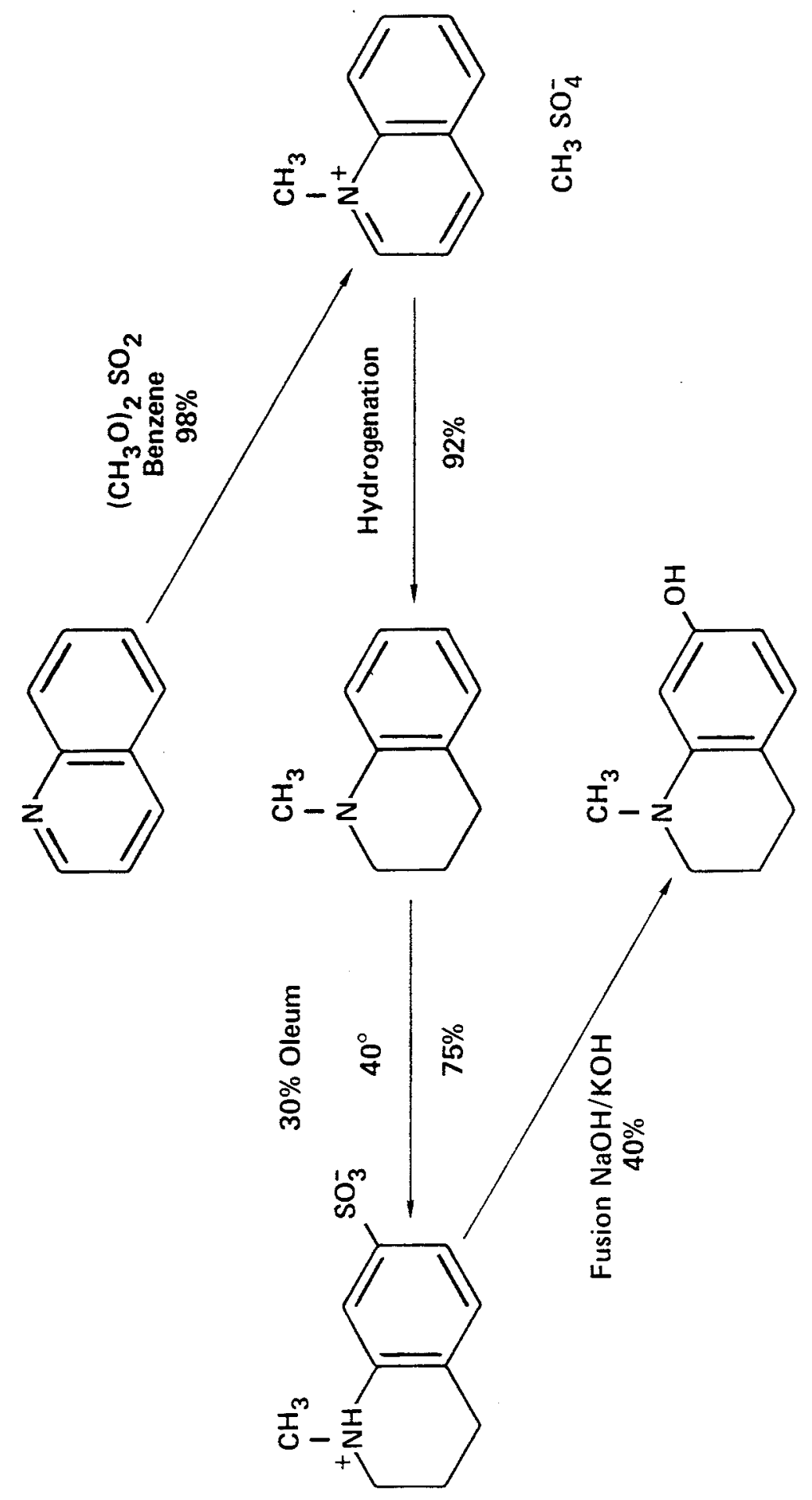

Figure 26 


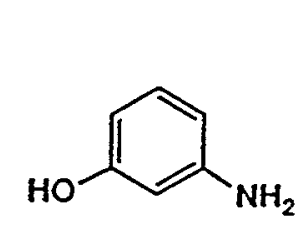

1

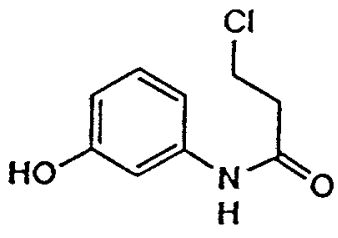

2

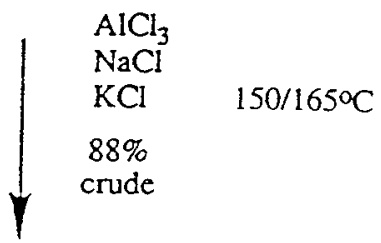

1) $\mathrm{BH}_{3}-\mathrm{Me}_{2} \mathrm{~S} /$ toluene<smiles>Oc1ccc2c(c1)NCCC2</smiles><smiles>CCC(=O)O[Na]</smiles><smiles>O=C1CCc2ccc(O)cc2N1</smiles>

4<smiles>O=C1CCc2c(O)cccc2N1</smiles> 


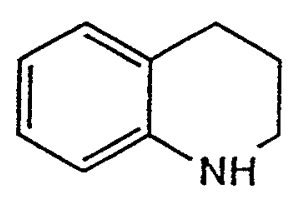

1<smiles>Nc1ccc2c(c1)NCCC2</smiles>

$\underline{3}$
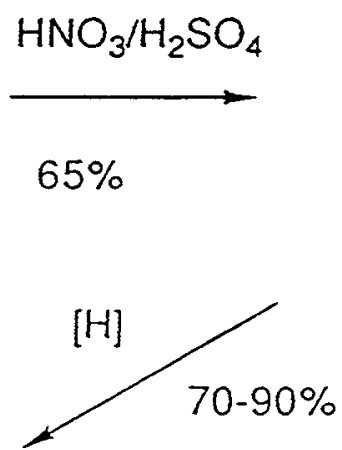

Aq. $\mathrm{H}_{3} \mathrm{PO}_{4}$

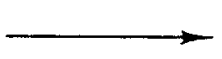

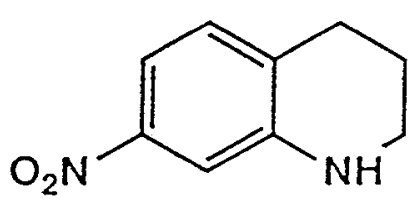

$\underline{2}$<smiles>Oc1ccc2c(c1)NCCC2</smiles>

$\underline{4}$ 
$\left(\mathrm{CH}_{3}\right)_{2} \mathrm{~N}-(\mathrm{CH}=\mathrm{CH})_{2} \overbrace{\substack{\mathrm{N}_{1}^{+} \\ \mathrm{CH}_{2} \mathrm{CH}_{3} \quad \mathrm{ClO}_{4}^{-}}}^{\text {Pyridine I }}$ LDS-698

Styryl 9

$\left(\mathrm{CH}_{3}\right)_{2} \mathrm{~N}-(\mathrm{CH}=\mathrm{CH})_{3}-\underset{\substack{\mathrm{N} \\ \mathrm{C} \mathrm{CH}_{2} \mathrm{CH}_{3} \quad \mathrm{ClO}_{4}^{-}}}{\mathrm{S}}$

LDS-820

$\left(\mathrm{CH}_{3}\right)_{2}$ 

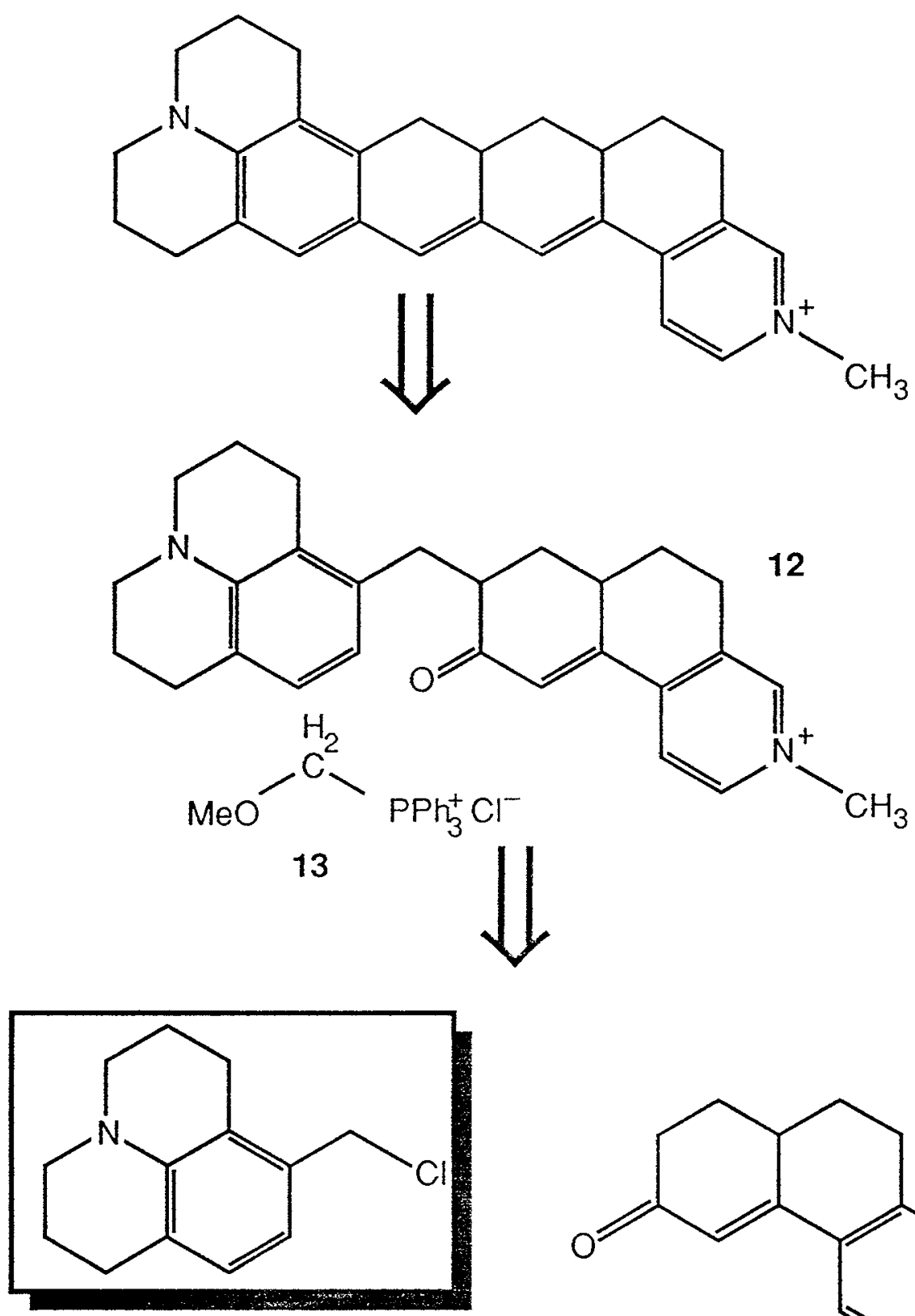

14

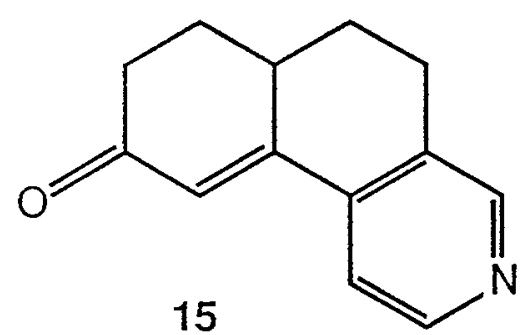

$\Downarrow$<smiles>C=CC(C)=O</smiles>

16

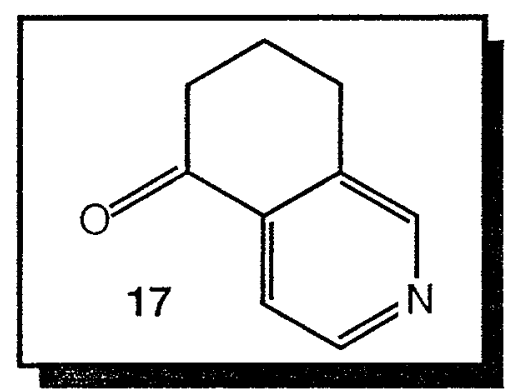



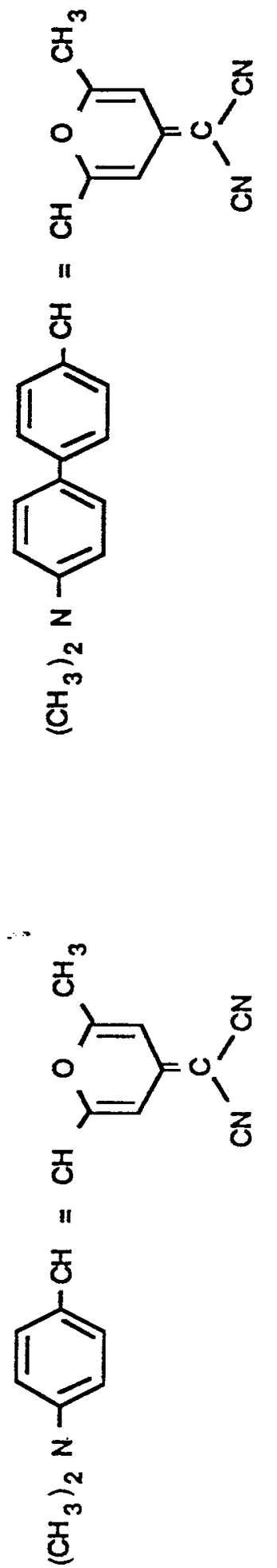

Figure 31 


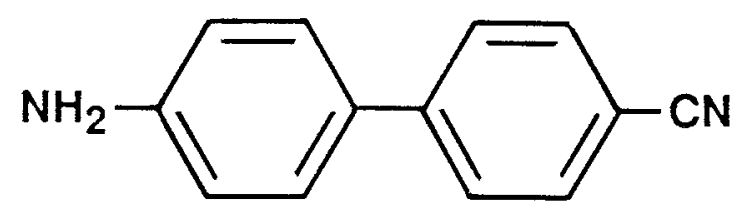

$\left(\mathrm{CH}_{3}\right)_{2} \mathrm{~N}$

$\left(\mathrm{CH}_{3}\right)_{2} \mathrm{~N}$ 


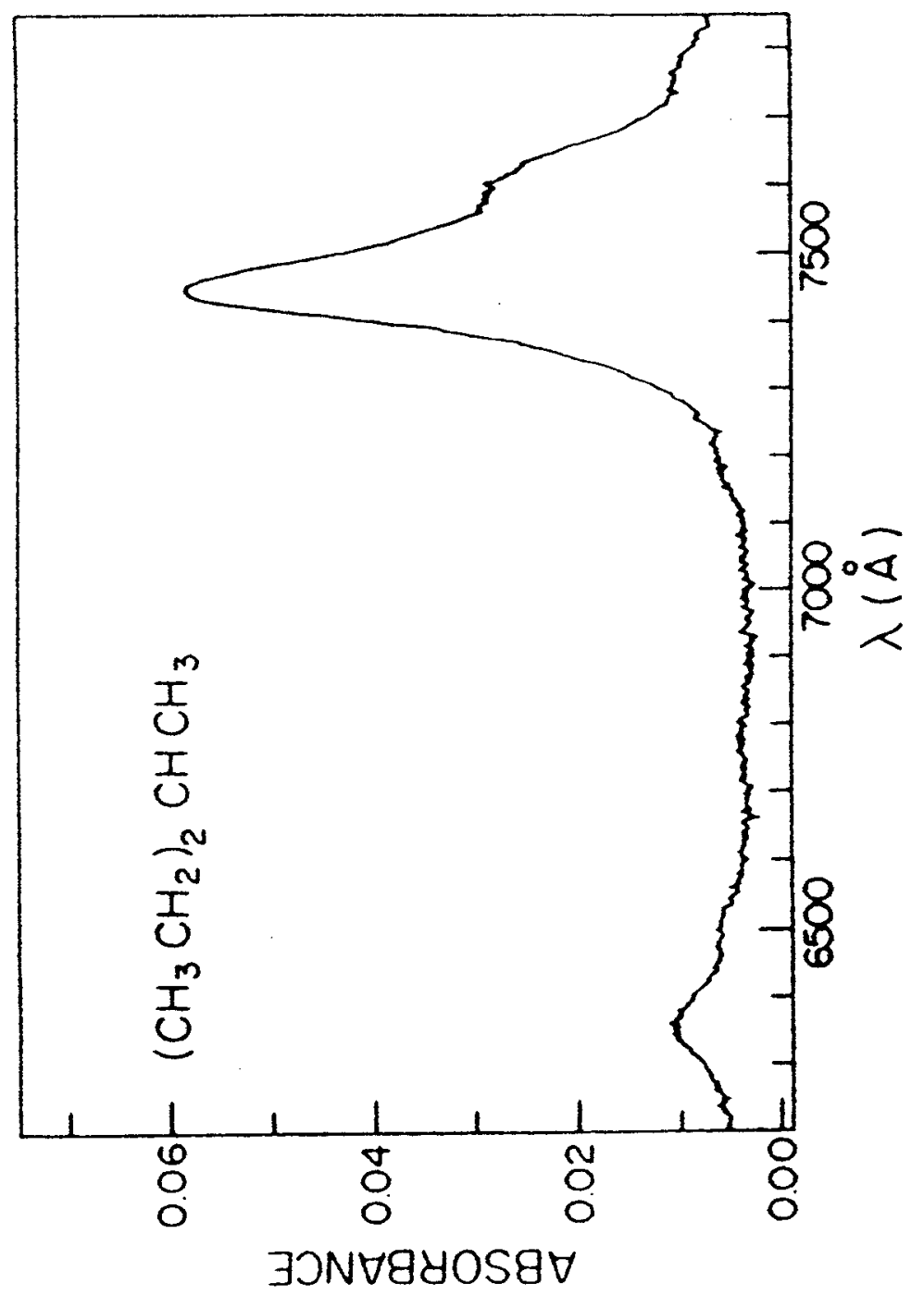

Figure 33 


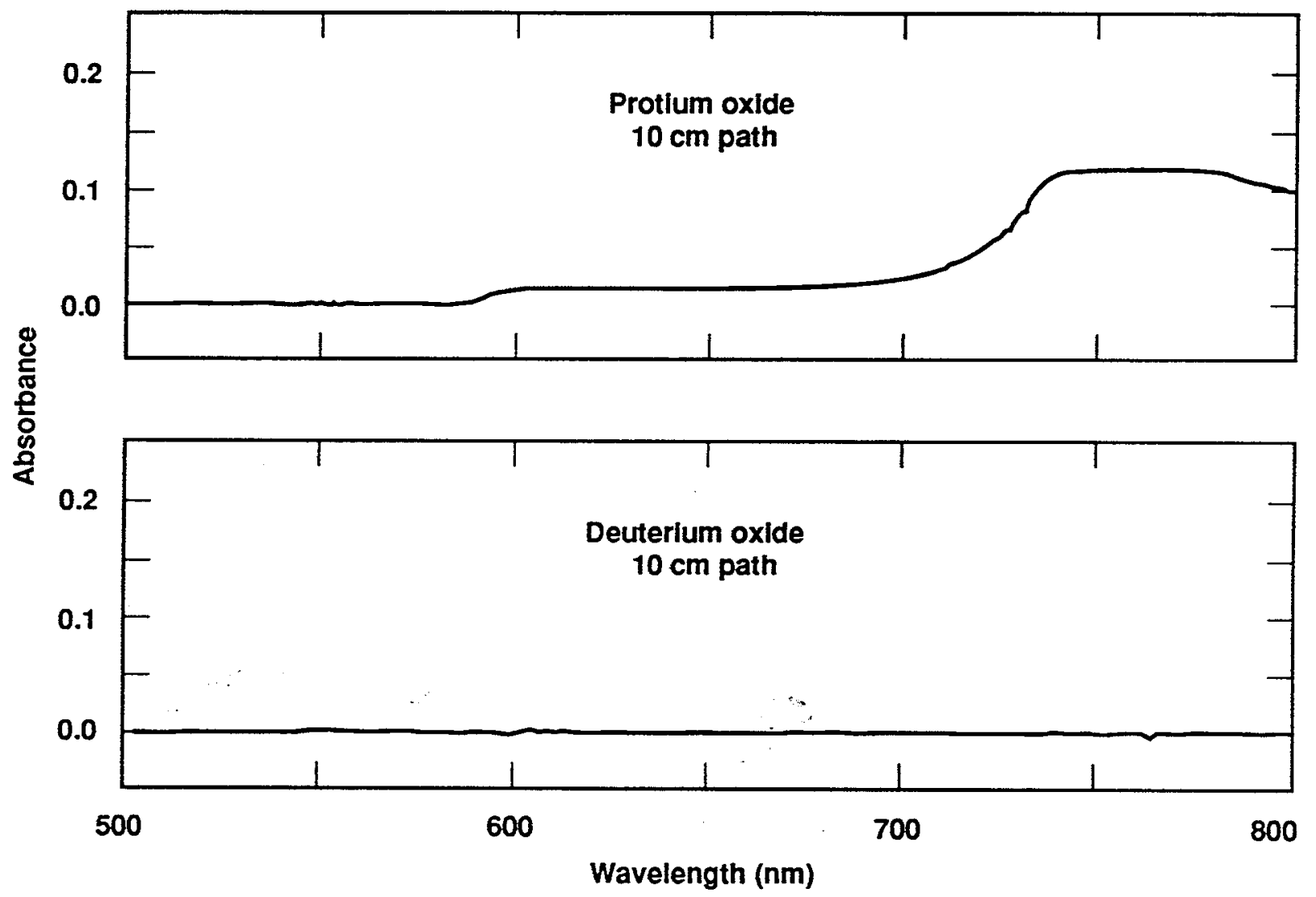

Figure 34 


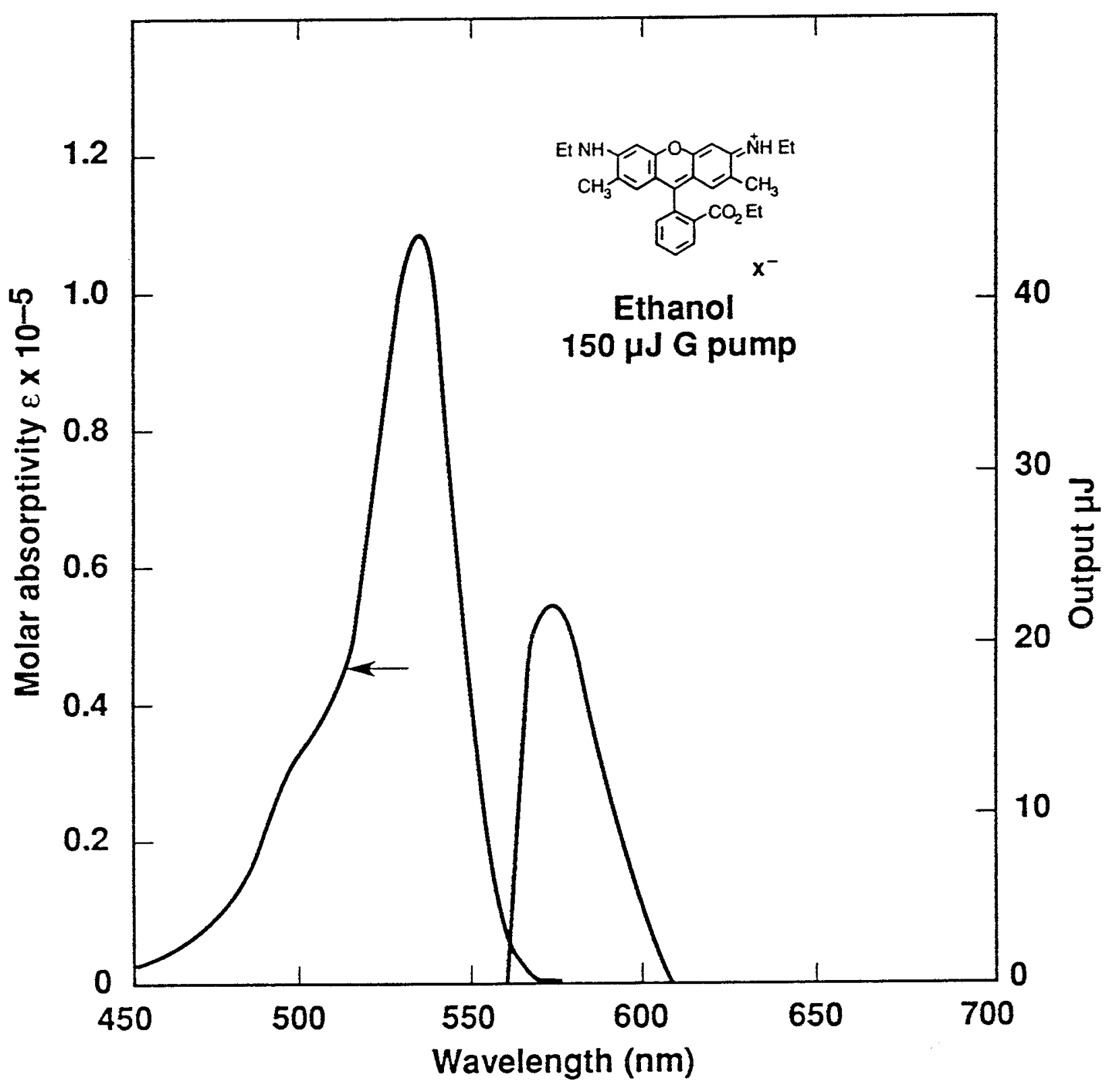



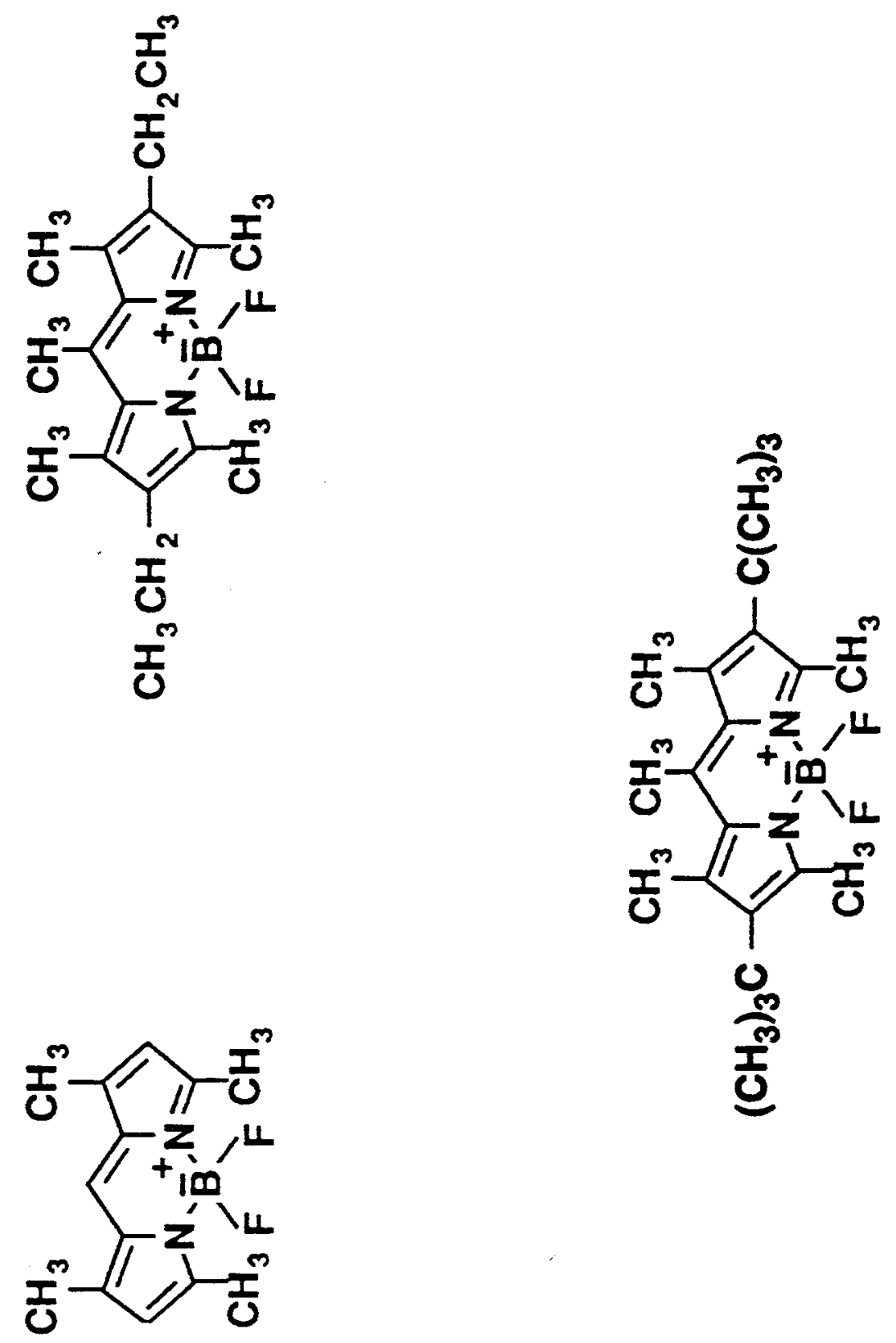


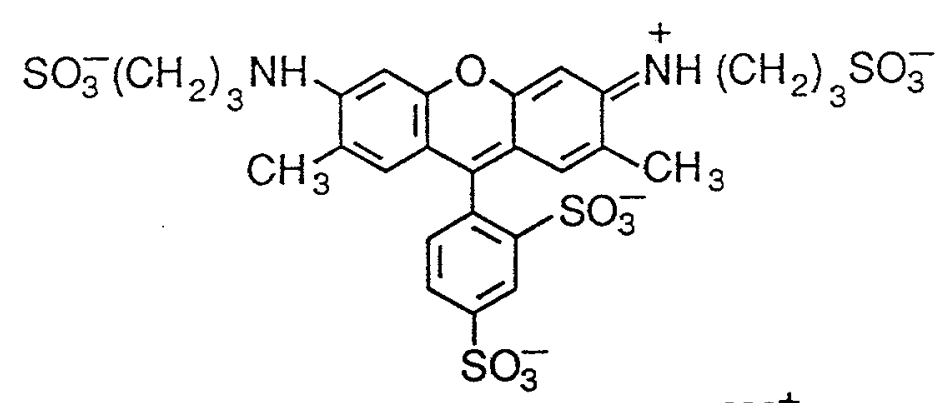

$3 M^{+}$

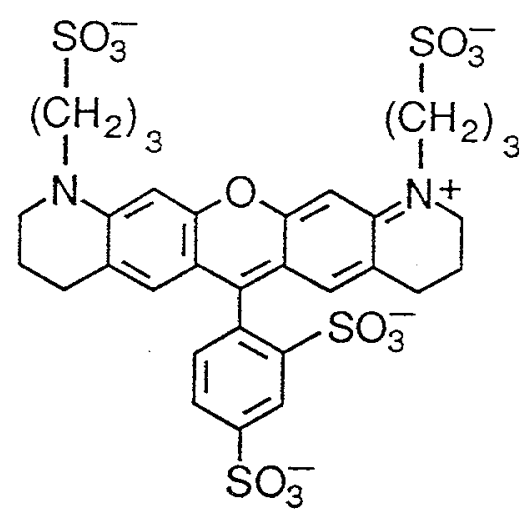

$3 M^{+}$

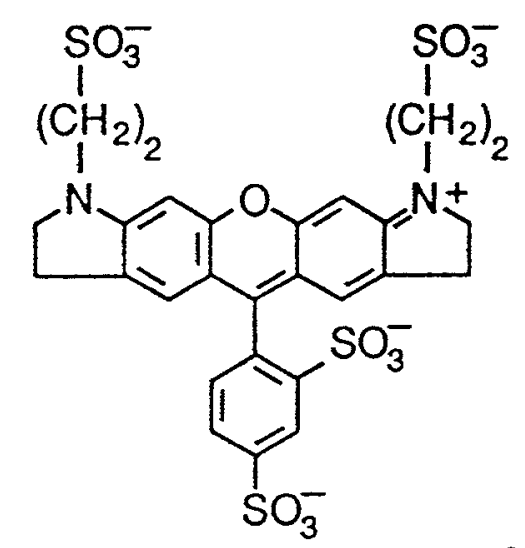

$3 M^{+}$

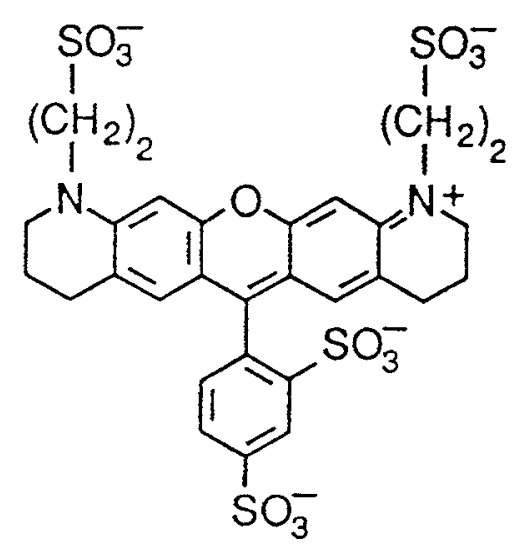

$3 M^{+}$

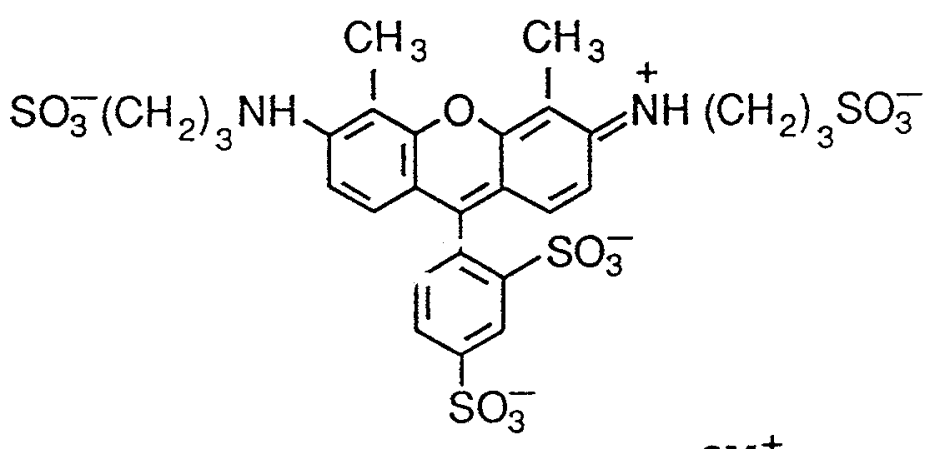

$3 M^{+}$

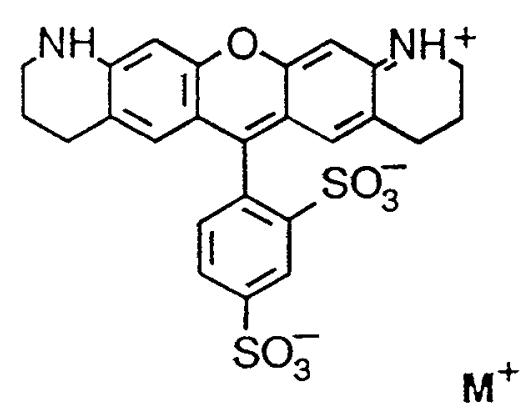

